\title{
Fundamentals of stem cells: why and how patients' own adult stem cells are the next generation of medicine
}

Correspondence

Dr. Eckhard Alt, MD 2210 Chilton Road Houston, TX 77019, USA Phone: $+1-504-988-3040$

Cell: +1-832-853-3898

E-mail: ealt@tulane.edu

\author{
Eckhard U. Alt ${ }^{1-4}$, Christoph Schmitz ${ }^{5}$ Xiaowen Bai ${ }^{1,3,6}$ \\ ${ }^{1}$ Heart and Vascular Institute, Department of Medicine, Tulane University Health Science \\ Center, New Orleans, LA, USA \\ 2 Sanford Health, University of South Dakota, Sioux Falls, SD, USA \\ ${ }_{3}^{3}$ University of Texas MD Anderson Cancer Center, Houston, TX, USA \\ ${ }^{4}$ Isar Klinikum Munich, Munich, Germany \\ ${ }^{5}$ Chair of Neuroanatomy, Institute of Anatomy, Faculty of Medicine, Ludwig-Maximilian \\ University Munich, Munich, Germany \\ ${ }^{6}$ Department of Cell Biology, Neurobiology \& Anatomy, Medical College of Wisconsin, \\ Milwaukee WI, USA
}

Various tissue resident stem cells are receiving attention from basic scientists and clinicians as they hold certain promise for regenerative medicine. This paper is intended to clarify and facilitate the understanding, development and adoption of regenerative medicine in general and specifically of therapies based on unmodified, autologous adipose-derived regenerative cells (UAADRCs). To this end, results of landmark experiments on stem cells and stem cell therapy performed in the labs of the authors are summarized, the most intriguing of which are the following: (i) vascular associated mesenchymal stem cells (MSCs) can be isolated from different organs (adipose tissue, heart, skin, bone marrow and skeletal muscle) and differentiated into ectoderm, mesoderm and endoderm, providing significant support for the hypothesis of the existence of a small, ubiquitously distributed, universal vascular associated stem cell with full pluripotency; (ii) the orientation and differentiation of MSCs are driven by signals of the respective microenvironment; and (iii) these stem cells irrespective of the tissue origin exhibit full pluripotent differentiation potential without any prior genetic modification or the need for culturing. They can be obtained from a small amount of adipose tissue when using the appropriate technology for isolating the cells, and can be harvested from and re-applied to the same patient at the point of care without the need for complicated processing, manipulation, culturing, expensive equipment, or repeat interventions. These findings demonstrate the potential of UA-ADRCs for triggering the development of an entire new generation of medicine for the benefit of patients and of healthcare systems.

Key words: adipose-derived; bone regeneration; cartilage regeneration; clinical application; clinical studies; differentiation; hair loss; induced pluripotent stem cells; maxillary sinus augmentation; osteoarthritis; pluripotency; regenerative cells; regenerative medicine; progenitor cells; scar tissue; stem cells; wound healing 


\section{Introduction}

Regenerative cell therapy, which refers to the therapeutic application of stem cells to repair diseased or injured tissue, has received increasing attention from basic scientists, clinicians and the public. Stem cells hold significant promise for tissue regeneration due to their innate ability to provide a renewable supply of progenitor cells that can form multiple cell types, whole tissue structures, and even organs. Stem cells are present in the human body at all stages of life from the earliest times of an embryo through adulthood and senescence.

Embryonic stem cells (ESCs), which can be derived from the blastocyst stage of mammalian embryos, exhibit remarkable developmental plasticity that enables them to differentiate into all types of cells present in the body (Vazin and Freed, 2010). However, several major issues, including ethical concerns, potential allogenic immune rejection, and the risk of teratoma formation have limited research and clinical application of therapies based on ESCs (c.f., e.g., Fujikawa et al., 2005; Swijnenburg et al., 2005; King and Perrin, 2014). Primarily due to these issues a major interest now largely shifted to stem cells derived from postnatal and adult tissues. Most prominently, researchers have identified in the vascular location of all organs and tissues a type of adult stem cell, commonly referred to as mesenchymal stem cells (MSCs) that exhibit significant potential for differentiation into a number of cell types (c.f., e.g., da Silva Meirelles, Chagastelles and Nardi, 2006; Bai et al., 2007; Ilmer et al., 2014). Although these adult stem cells are essentially ubiquitous, isolation from critical organs such as bone marrow, skin, skeletal muscle, liver, heart or brain has limited practicality. This is due to the fact that such isolation carries a potential risk of damage to the donor and often does not yield enough cells. As such, it is typically required to expand cells in culture in order to obtain the desired number of cells for the respective therapeutic application. A highly attractive alternative with great clinical significance is to isolate these adult stem cells from adipose tissue (outlined in detail in Section 4 of this article).

The different terms and definitions used in this article to describe adult stem cells are summarized in Figure 1. Ethical approvals are summarized at the end of the manuscript.

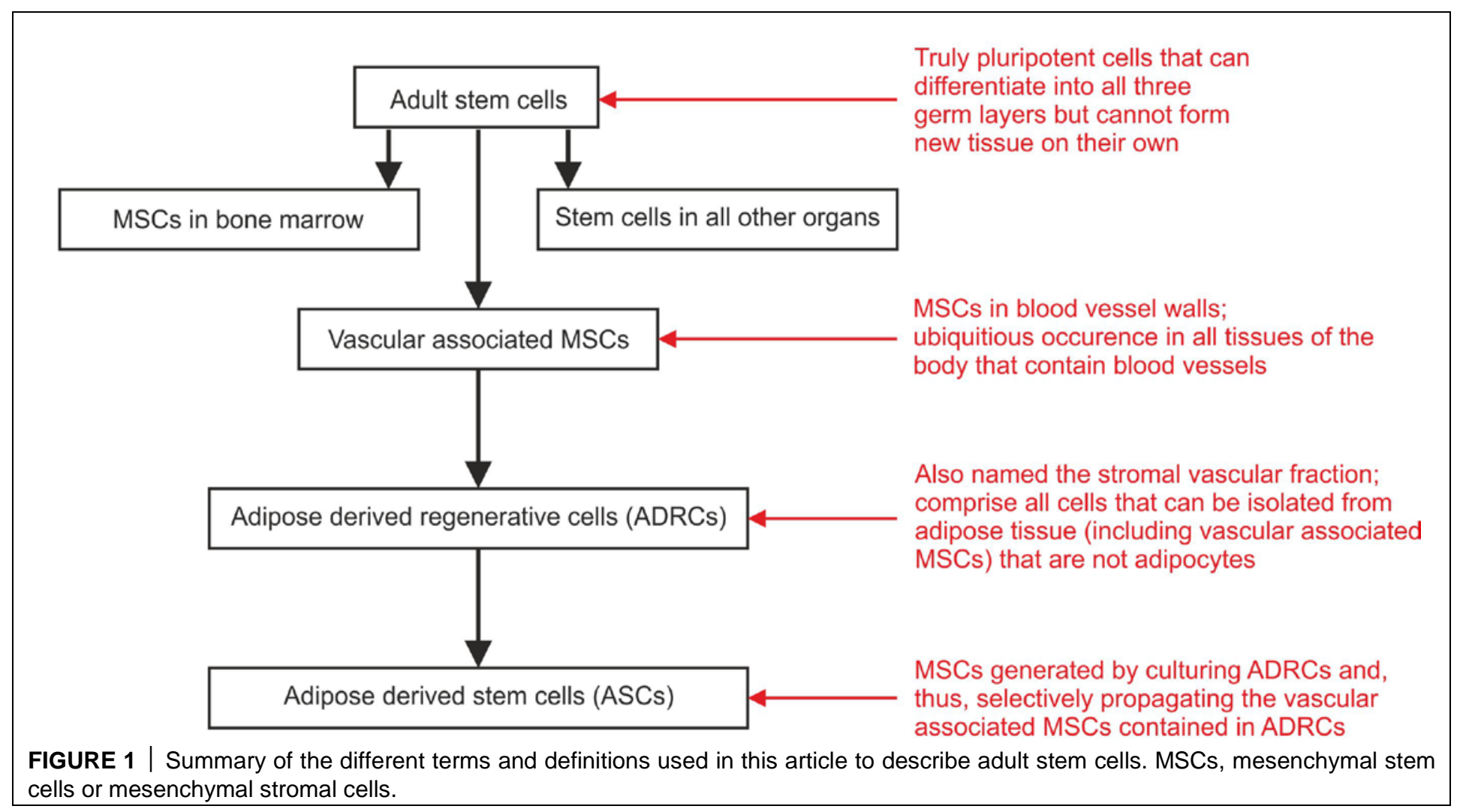




\section{The definition of the term stem cells}

\subsection{The current state of confusion about the term stem cells}

Approximately 50 years ago Friedenstein et al. (1968; 1974) described multipotent cells derived from bone marrow stroma that were adherent to plastic and had the ability to differentiate into cells other than hematopoietic lineages. Since then, our knowledge about stem cells has been steadily growing. However, the current definition of the term stem cells as given by Dominici et al. (2006), that describes MSCs as being adherent to plastic, expressing the surface markers CD73, CD90 and CD105, and having the ability to differentiate into osteoblasts, adipocytes and chondrocytes, is not quite complete. This is partly due to the fact that, for example, fibroblasts express these surface markers as well, without having the ability to transdifferentiate into other lineages or being MSCs (Alt et al., 2011). The definition of the term stem cells primarily by surface markers (c.f. Dominici et al., 2006) is not sufficient, especially as we have learned in the meantime that the true pluripotent stem cells do not yet express CD73, CD90 and CD105 (outlined in detail in Section 3 of this article). Rather, expression of cell surface markers is a dynamic process. When cultured in fetal bovine serum (FBS) or platelet lysate culture media, MSCs can turn on new surface markers. Alternatively, MSCs in culture can lose their surface marker expression, such as for example the loss of the previously expressed progenitor marker CD34 or the endothelial progenitor marker CD31. In addition, the specific type of culture media (FBS or defined serum free media [SFM]) and the surface characteristics of a culture dish strongly impact on visual appearance, growth rate and surface marker expression of MSCs. For example, MSCs are adherent to plastic and display a typical, spindle shaped appearance when cultured in FBS (Fig. 2a,c). In contrast, they form spheroids when cultured in SFM (Fig. 2b,d). Besides this, the cellular growth rate determined by the G1, S and $\mathrm{M}$ phases of the cell cycle considerably differ between MSCs cultured in FBS (high growth rate) compared with MSCs cultured in SFM (very low growth rate) (data not shown).

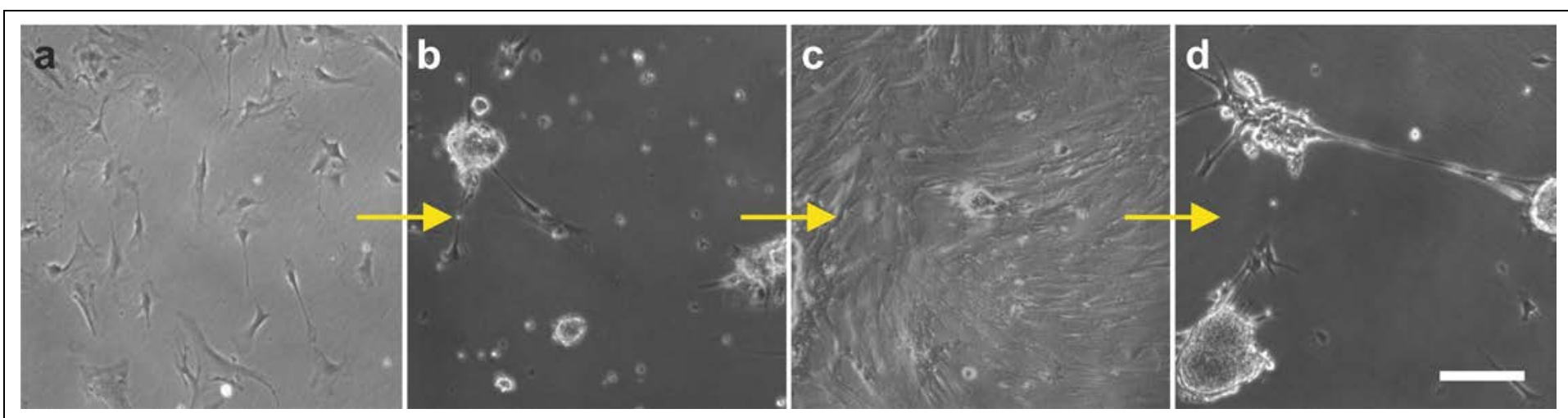

FIGURE 2 | Change in the morphology of rat adipose-derived stem cells cultured first in fetal bovine serum (FBS) for 14 days (a), then in serum free medium (SFM) for 24 hours (b), and then again in FBS for one week (c). Afterwards, then transfer to SFM again induced a spheroid like appearance (d). The scale bar represents $100 \mu \mathrm{m}$.

One of the major current problems in understanding stem cells is based on different and varying definitions of the meaning of the term stem cells (e.g., Pittenger et al., 1999; Phinney and Prockop, 2007; Bourin et al., 2013). The way the term stem cells is often used by researchers and the public confuses true stem cells with progenitor cells. True stem cells are defined as being able to differentiate into all three germ layers (e.g., Bai et al., 2007; Ratajczak, 2015). In contrast, progenitor cells are already on a pre-determined pathway to become a differentiated cell and have lost their ability to decide what they want to be 'in life'. In other words, in contrast to true stem cells, progenitor cells are typically determined to differentiate and develop into a defined cell type and primarily have lost their multipotency. For example, in bone marrow, more than $99 \%$ of the cells are not true stem cells, but primarily hematopoietic progenitor cells (e.g., Song, Prantl and Alt, 2010; Bruno et al., 2014). Accordingly, progenitor cells have already started a pathway of lineage-committed differentiation. In case of bone marrow derived cells, these hematopoietic progenitor cells (often incorrectly labeled as stem cells) started to differentiate into future hematopoietic cells of the white, red or platelet lineage. Pending on their progress in maturation in this differentiation process, these cells are no longer able to revert their pathway of differentiation. At best, they are able to vary somewhat within the same germ layer of differentiation, but typically stay within the same lineage (Ricci-Vitiani et al., 2010; Wang et al., 2010). Much of the confusion about the term stem cells 
originates from this mix-up of the definition of true stem cells with progenitor cells in the literature (c.f., e.g., Bourin et al., 2013; Caplan, 2017; Velten et al., 2017; see also Alt, 2015).

\subsection{The limited significance of induced pluripotent stem cells for the practice of medicine}

Another problem is the incorrect public belief that naturally no stem cells would exist that are able to differentiate into all three lineages without being first modified or genetically altered. The euphoria around the so-called induced pluripotent stem cells (iPS cells) (that resulted in the granting of the Nobel Prize in Physiology or Medicine 2012) has led to a direction in the last couple of years in research that will likely not significantly change the practice of medicine. For more than ten years it has been demonstrated many times that naturally there are pluripotent stem cells which are able to differentiate into all three germ layers without being first genetically modified (c.f., e.g., Pittenger et al., 1999; Zuk et al., 2001; Song, Prantl and Alt, 2011). Hence, it becomes clear that the need for genetically manipulated iPS cells (in which first an artificial [induced] overexpression of embryonic genes like Oct4, Klf4, Sox2 and/or cMyc is necessary; c.f., e.g., Jullien et al., 2011; Heffernan, Sumer and Verma, 2011; Shi et al., 2017) is not required for the practice of medicine. Rather, the universally distributed true stem cells we refer to in this article are naturally able to differentiate into all three germ layers and into any tissue of the body under guidance of the local microenvironment, without requiring prior overexpression of embryonic genes or any prior artificial genetic manipulation.

Another important aspect regarding iPS cells is that the genetic manipulation of overexpression of embryonic genes in these cells makes them less likely to enter the practice of medicine due to the complexity of the procedure. Besides this, there are concerns that iPS cells can demonstrate features similar to cancer cells (c.f., e.g., Takahashi et al., 2007; Yu et al., 2007; Lee et al., 2013). While the iPS cell technology will most likely not advance to a stage where therapeutic transplants are deemed safe (Lee et al., 2017), iPS cells are certainly supportive in helping to better understand differentiation pathways of stem cells and patient-specific bases of diseases, as well as to develop personalized drug discovery efforts (c.f., e.g., Marsoner, Koch and Ladewig, 2018).

Dr. Paul Knoepfler and his team at UC Davis School of Medicine (Davis, CA, USA) were the first to demonstrate that induced pluripotency and oncogenic transformation are related processes when comparing the transcriptomes of iPS cells with the transcriptomes of cancer cells (Riggs et al., 2013; see also Steinemann, Göhring and Schlegelberger, 2013; Tung and Knoepfler, 2015). Collectively, these studies have established a need for caution when conducting clinical trials using iPS cell based therapies.

\subsection{Important differences regarding pluripotency and multipotency between embryonic stem cells, adult stem cells and cancer cells}

There are important differences regarding totipotency, pluripotency and multipotency between embryonic, fetal and adult stem cells. A totipotent cell (found in the morula stage of embryonic development) can differentiate into any type of cell in the body. A pluripotent cell (found in the blastocyst stage of embryonic development) possesses the intrinsic pattern and existing guidelines for building a new organ which is not yet existing. Pluripotency here means that the embryonic stem cells can develop into any tissue and organ of the three germ layers (i.e., ectoderm, mesoderm and endoderm), without that these tissues or organs yet exist.

In a similar way as in embryonic stem cells, pluripotency is naturally present in adult stem cells as evidenced by their ability to differentiate into ectodermal, mesodermal and endodermal lineages. The difference compared to embryonic stem cells, however, is that adult stem cells cannot form new tissue on their own. They miss the intrinsic program of embryonic stem cells but instead depend on the signaling from the respective microenvironment (outlined in detail in the following sections). This means that adult stem cells may obtain any of the three lineages but depend on constant induction of differentiation and re-confirmation by signals released and communicated from the local microenvironment (c.f., e.g., Rezza, Sennett and Rendl, 2014; Dong et al., 2015; Wabik and Jones, 2015). If this information and confirmation is missing or ceases, adult stem cells stop differentiating (Trosko, 2014; Zhang et al., 2015).

In contrast, cancer cells with upregulated embryonic genes like Oct4 can overcome this tissue microenvironment dependency and form a tissue of their initial tissue type, resulting in a metastasis (Tai et al., 2004; Ilmer et al., 2014). For example, pancreatic tumor cells can grow in the liver, forming a metastasis. In contrast, normal pancreatic progenitor cells stop differentiation and undergo apoptosis when implanted into the liver. A continuous lineage specific differentiation only occurs if it is supported by continuous signaling from the respective microenvironment. For example, the injection of cells derived from the bone marrow (which for their majority consist of hematopoietic progenitor cells) into a knee would result in a significant 
inflammatory accumulation of white blood cells in the knee. However, because the local microenvironment does not support the continuing differentiation of these hematopoietic progenitor cells, they would become apoptotic. In fact, only true stem cells are able to continue their expected differentiation pathway as supported by the local microenvironment (e.g., Phinney and Prockop, 2007; Kara et al., 2011; Malliaras et al., 2013). This is one of several reasons why adult stem cell therapy with fresh, unmodified autologous stem cells is very safe (e.g., Ra et al., 2011; Hoffman and Dow, 2016; Toyserkani et al., 2017). Safety concerns have only been raised with cultured adult stem cells since as with higher passages increased rates of potential malignant transformation may occur (e.g. Røsland et al., 2009; Xu et al., 2012; Pan et al., 2014).

\section{The ubiquitous occurrence of stem cells in tissue that contains blood vessels}

\subsection{Location and origin of tissue resident stem cells}

Stem cells have been found and described at many sites in the human body. However, many publications assume that stem cells in specific organs are related and specific to the respective tissue or organ. The hypothesis of universal, vascular associated MSCs that are ubiquitously distributed has been less adopted and accepted, both by the scientific community and the public.

For many years MSCs were considered to be located primarily in bone marrow. In recent years, however, stem cells have been demonstrated to exist in many organs. This is not so much due to the fact that each organ contains its specific individual type of stem cells, but rather that there is a ubiquitous distribution of the same kind of MSCs throughout the human body.

Blood vessels are the initial structures to be formed if a new organ is developing in an embryo. The presence of stem cells in the vascular location allows equal distribution of stem cells with pluripotent or multipotent capacity throughout the body. These cells serve as a repertoire for renewal of the respective tissue and organs for the rest of the life of the individual.

For example, a certain number of MSCs per gram tissue can be isolated from rat brain tissue. However, when preparing a microvascular preparation of rat brain tissue in which only microvessels were remaining and the rest of the brain tissue was discarded - we found that the resulting number of MSCs per gram tissue increased by several potencies, indicating that the majority of MSCs are indeed located or associated with the vascular structure (Alt et al.; unpublished results). Moreover, we were able to demonstrate that the same vascular associated MSCs can be isolated from blood vessels independent of the organ or tissue they are derived from (outlined in detail in Fig. 14 below).

\subsection{Existence of mesenchymal stem cells in blood vessels}

Results of studies from our laboratories demonstrate that identical vascular associated MSCs can be isolated from all blood vessels, independent of the organ or tissue they are derived from. This was demonstrated with cells derived from both human and animal tissue. Specifically, the MSCs were isolated from microvessels. Figure 3 shows a microvessel preparation and a phase contrast image of such a microvessel from a rat brain.

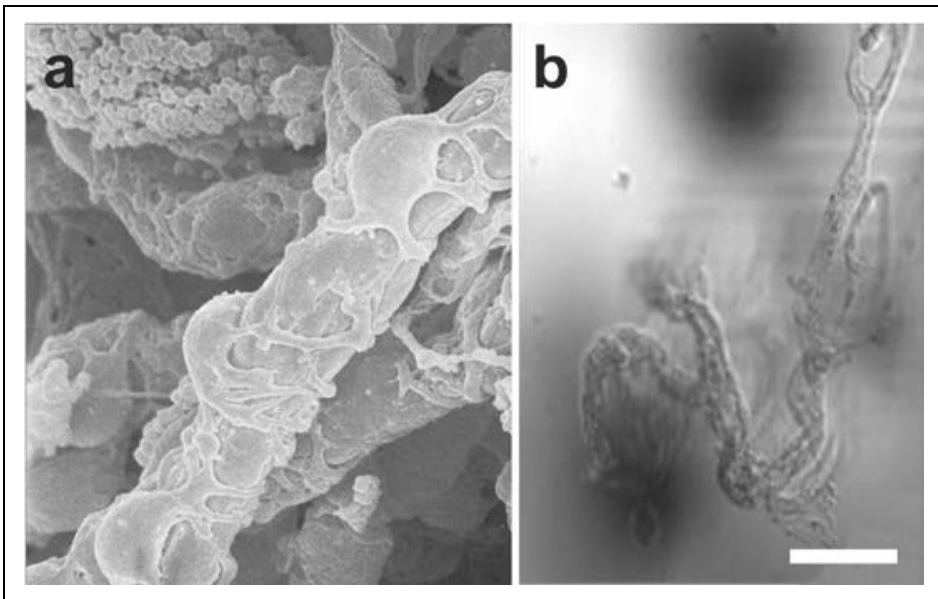

FIGURE 3 Microvessel-associated cells (microvessel isolated from a rat brain) represent a universal resource within the entire body. (a) Scanning electron microscopic image of a microvessel. (b) Phase contrast image of a microvessel as used for further analysis. The scale bar represents $5 \mu \mathrm{m}$ in (a) and $40 \mu \mathrm{m}$ in (b).

Figure 4 shows a scanning electron microscopic image of cells that were isolated from human abdominal adipose tissue by enzymatic release, and were imaged just minutes after isolation and plating. These cells (which represent the so-called stromal vascular fraction) were not cultured but freshly isolated. The presence of a composition of different cells is found in this image. One can recognize larger cells that exhibit a rough structure ('P' in Fig. 4). These cells are progenitor cells that have already started to build actin filaments (white arrows in Fig. 4) in order to enhance their adherence to the extracellular matrix on which they were seeded. Besides this, some of these cells have started to communicate through microtubular structures (arrowhead in Fig. 4). In addition there are also lymphocytes (' $L$ ' in Fig. 4) as well as small cells (' $S$ ' in Fig. 4) present. These small cells show a relatively smooth surface and are limited in their ability to adhere to the 
extracellular matrix. They do not show exosomal structures on their surface as some of the larger cells do (' $E$ ' in the high-power inset in Fig. 4). In addition, dying cells are found which are devolving into apoptotic bodies ('D' in Fig. 4).

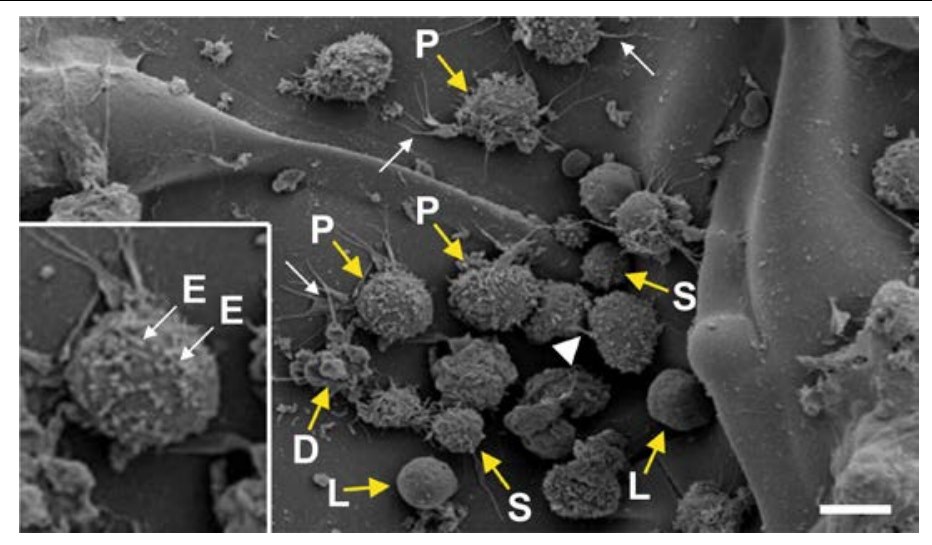

FIGURE 4 Scanning electron microscopic image of the cellular composition of the stromal vascular fraction obtained from human abdominal adipose tissue. Abbreviations: $\mathrm{P}$, progenitor cells; S, small cells; D, dying cells; L, lymphocytes; E, exosomes. The white arrows point to actin filaments, and the white arrowhead to a micro-channel between two cells. Details are provided in the main text. The scale bar represents $10 \mu \mathrm{m}$ (20 $\mu \mathrm{m}$ in the high-power inset).
Analyzing the individual cells shown in Figure 4 in more detail revealed that approximately $20 \%$ of the cells were 'naked' and smooth on their surface, most likely representing white blood cells such as lymphocytes (' $\mathrm{L}$ ' in Fig. 4). The content of the small assumed MSCs ('S' in Fig. 4) was about $10 \%$ of the cell population shown in Figure 4. This demonstrates that, following enzymatic preparation, the stromal vascular fraction of human abdominal adipose tissue is composed of white blood cells and includes small MSCs and larger cells, most likely progenitor cells. However, the composition between the different cellular elements varies with the tissue these cells are obtained from.

A more precise location of the cells in the vascular structures is revealed by multi-colored immunohistochemistry of a small arteriole (Fig. 5). Cell nuclei (blue in Fig. 5) and smooth muscle antigen (SMA) (green in Fig. 5) define the structure of the arteriole. Furthermore, the location of laminin (purple in Fig. 5) correlates with the border between the endothelial basal lamina (representing the intima) and the media containing the smooth muscle cells (note that in this position also the internal elastic lamina is found; c.f., e.g., Di Russo et al., 2017). Of note, neuron-glial antigen 2 (NG2) (red in Fig. 5) was found in close proximity to laminin, and most likely represents the vascular associated MSCs.

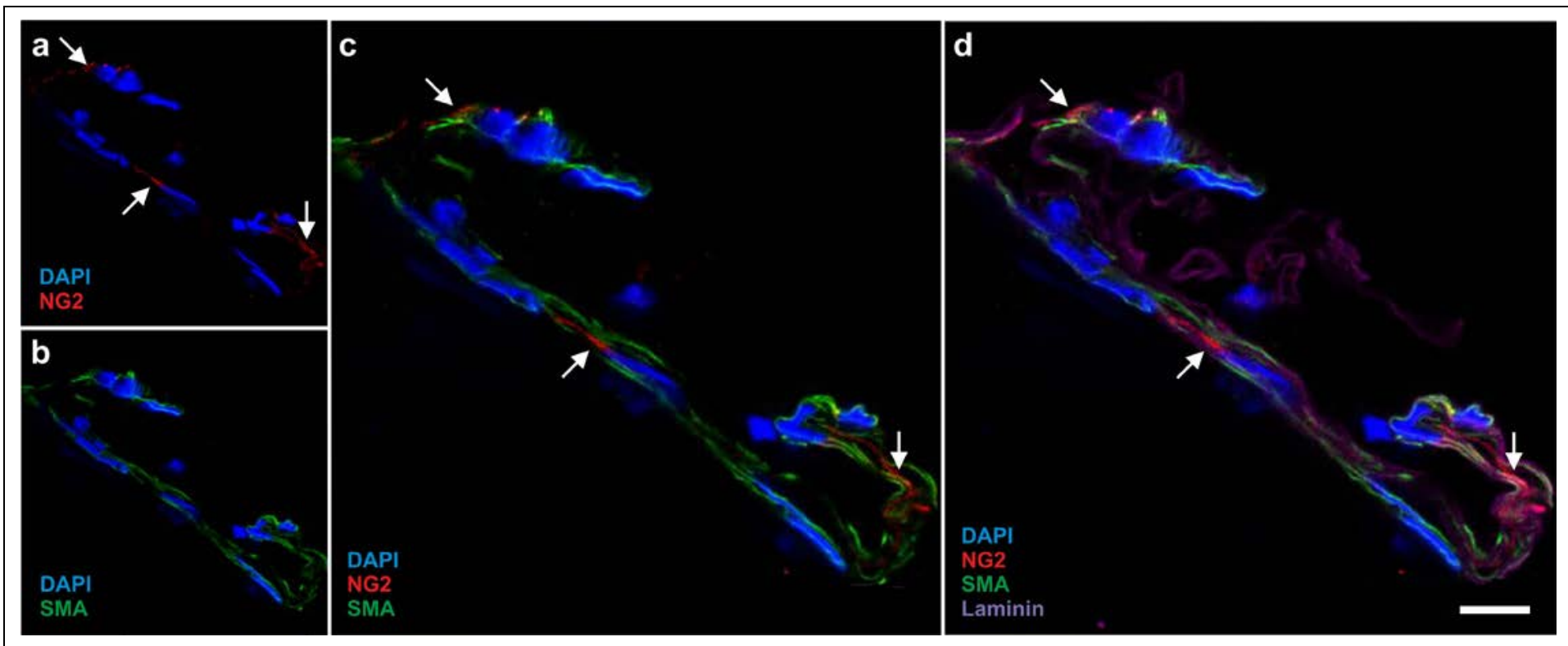

FIGURE 5 | Immunofluorescent detection of neuron-glial antigen 2 (NG2) (red in a,c,d; arrows), smooth muscle antigen (SMA) (green in (b,c,d) and laminin (purple in $d$ ) in the wall of a small human arteriole (cell nuclei in blue). The scale bar represents $20 \mu \mathrm{m}$ in (a,b) and $10 \mu \mathrm{m}$ in $(\mathrm{c}, \mathrm{d})$.

NG2 has long been associated with pericytes (e.g., Crisan et al., 2012; Binamé, 2014; Sá da Bandeira, Casamitjana and Crisan, 2017). However, pericytes are fully differentiated cells that already have a terminal, differentiated purpose in life, namely the formation of capillaries together with endothelial cells (c.f., e.g., Avolio and Madeddu, 2016). Thus, there are almost probably no pericytes at the position of the NG2 signal in Figure 5, as 
could be concluded from, e.g., Fig. 1B in Crisan et al. (2012) (note that in Fig. 1 in Avolio and Madeddu (2016) no pericytes were indicated at this position). Rather, it is much more likely that the vascular associated MSCs are also immunopositive for NG2 and, thus, NG2 is expressed by more cells than just by pericytes. This would also clearly contradict statements by, e.g., Crisan et al. (2012) that pericytes and adventitial perivascular cells express in situ and in culture markers of MSCs and display capacities to differentiate towards osteogenic, adipogenic and chondrogenic cell lineages, and by Sá da Bandeira, Casamitjana and Crisan (2017) that pericytes are precursors of MSCs that are capable of differentiating into osteoblasts, adipocytes and chondrocytes.

In fact, different populations of pericytes and pericytelike progenitor cells were described. The best studied pericyte is part of the typical capillary structure formed by pericytes together with endothelial cells (e.g., Sims, 1986; Diaz-Flores et al., 1991; Guillemin and Brew, 2004). The second type is located at the surface of small blood vessels, partly taking over vessel regulation (e.g., Fernández-Klett and Priller, 2015). Besides this, pericytelike progenitor cells were described in the adventitia of larger vessels (c.f., e.g., Avolio and Madeddu, 2016). However, all of these types of pericytes have positions in the wall of capillaries or larger vessels that are clearly distinct to the position of the NG2-positive cells shown in Fig. 5. Other stainings and flow cytometric analyses showed that the vascular associated MSCs are additionally positive for Nestin (Fig. 6), Oct4 (Alt et al., 2011), Sca1 (Holmes and Stanford, 2007) and SSEA4 (D'Ippolito et al., 2006).

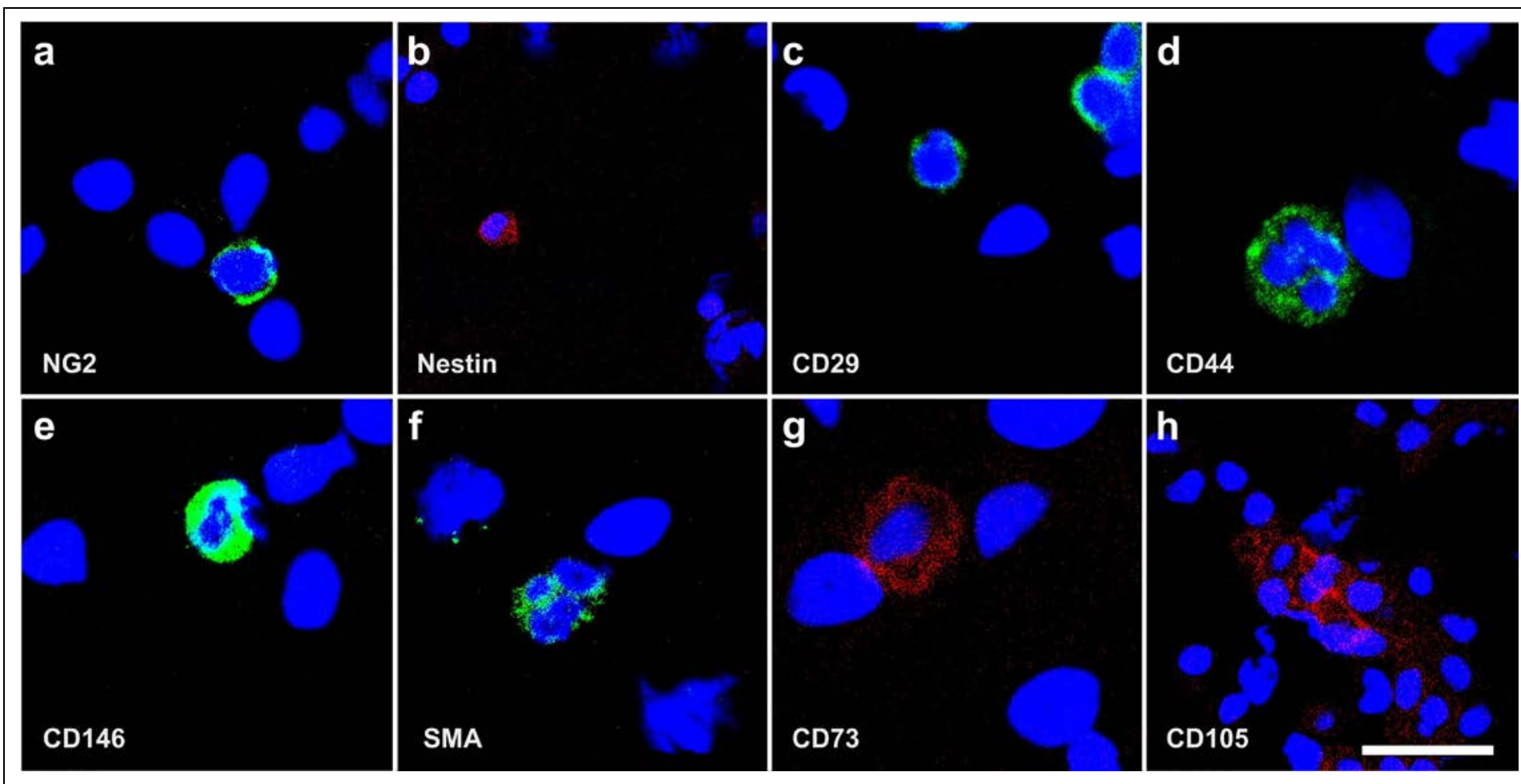

FIGURE 6 | Immunofluorescent detection of neuron-glial antigen 2 (NG2) (a), Nestin (b), CD29 (c), CD44 (d), CD146 (e), smooth muscle antigen (SMA) (f), CD73 (g) and CD105 (h) in human cells that were freshly isolated from adipose tissue. Note the very small cytosol of the cells that were immunopositive for NG2, Nestin and CD29 (a-c). The scale bar represents $20 \mu \mathrm{m}$ in (a,e,f), $40 \mu \mathrm{m}$ in (b), $26 \mu \mathrm{m}$ in (c), $15 \mu \mathrm{m}$ in (d), $18 \mu \mathrm{m}$ in (g) and $36 \mu \mathrm{m}$ in (h).

When cells that were freshly isolated from adipose tissue are analyzed with immunohistochemistry there are cells of different size, expressing different surface markers (Fig. 6).

The very small cells express the aforementioned NG2 signal (Fig. 6a) as well as Nestin (Fig. 6b). Nestin is an early marker of neural stem/progenitor cells as well as of proliferative endothelial cells (Suzuki et al., 2010). These cells have a tiny cytosol compared to the nucleus and to other more differentiated cells. Also, cells immunopositive for CD29 (integrin $\beta 1$ ) exhibit this kind of small cytosolic immunostaining (Fig. 6c). Together with CD49e (integrin $\alpha-5)$ CD29 forms integrin $\alpha 5 \beta 1$, the primary receptor for fibronectin (e.g., Clark, 1990; Serini, Valdembri and Bussolino, 2006; Vega and Schwarzbauer, 2016). Most probably the latter attaches the vascular associated MSCs to the extracellular matrix within the vessel wall. This is supported by the fact that SPARC (secreted protein acidic 
and rich in cysteine; also known as osteonectin) (c.f., e.g., Lane and Sage, 1994; Murphy-Ullich and Sage, 2014) can mobilize stem cells that are contained in adipose tissue through its effect on integrin $\alpha 5 \beta 1$ (Nie et al., 2008; Tseng and Kolonin, 2016), providing a functional basis for the regulation of the contribution of these stem cells to tissue and organ repair by SPARC. The latter is synthesized by several types of cells, including osteoblasts and odontoblasts (Holland et al., 1987), endothelial cells and fibroblasts (Brekken and Sage, 2001), but also macrophages (e.g., Chiodoni, Colombo and Sangaletti, 2010) and infiltrating leukocytes (Bradshaw, 2016). Thus, SPARC may represent a key regulator in making the vascular associated MSCs a replacement source responsive to the signals of the surrounding tissue.

It is of note that SPARC is also expressed by ASCs in vitro (Shaik et al., 2018). Moreover, the SPARC-related modular calcium-binding protein 1 (SMOC1), a member of the SPARC family and serving as a regulator of osteoblast differentiation, was found in the secretome of bone marrow derived MSCs (Choi et al., 2010). Thus, SPARC may play a pivotal role in both affecting the properties of MSCs in terms of proliferation and differentiation based on cues from the extracellular environment, as well as in paracrine activities of MSCs, impacting upon the activities of other cells in the local microenvironment (Kusuma et al., 2017).

\subsection{The hypothesis of a universal, vascular associated mesenchymal stem cell}

Figures 7 and 8 illustrate the principle of location and surface marker expression of the vascular associated MSCs. Figure 7 shows the endothelial basal lamina in black and the endothelial cells on the luminal side of the endothelial basal lamina in gray. We postulate that the vascular associated MSCs reside opposite to the endothelial cells on the abluminal side of the endothelial basal lamina, towards the smooth muscle cell layer and embedded within those. This is in contrast to other descriptions in the literature that vascular associated MSCs, presumably immunopositive for pericyte markers, would be located in the adventitia (e.g., Avolio and Madudda, 2016; Corselli et al., 2012; de Souza et al., 2016).

The vascular associated MSCs are small, which allows them to migrate through tissue in order to help maintaining tissue homeostasis. When these cells leave their quiescent location (i.e., their primary niche depicted in Fig. 8) they start to migrate, followed by proliferation which is primarily under control of the Wnt signaling pathway (e.g., Willert et al., 2003; Coudreuse and Korswagen, 2007; Neth et al., 2007), and finally differentiation. The location of proliferation may be called the secondary niche (Fig. 8), in contrast to the primary niche that is assigned to the vessel wall (Figs 7 and 8). The cells can leave their secondary niche and differentiate in the tertiary niche (Fig. 8) into their final lineage. The tissue specific differentiation pathway is controlled by signaling from the cells' new microenvironment, including micro-RNA and transcription factors (c.f., e.g., Rezza, Sennett and Rendl, 2014; Dong et al., 2015; Wabik and Jones, 2015). This principle highlights the regenerative power that exists in every organ. Throughout life replacing cells exist that can be locally mobilized upon need for tissue renewal and repair.

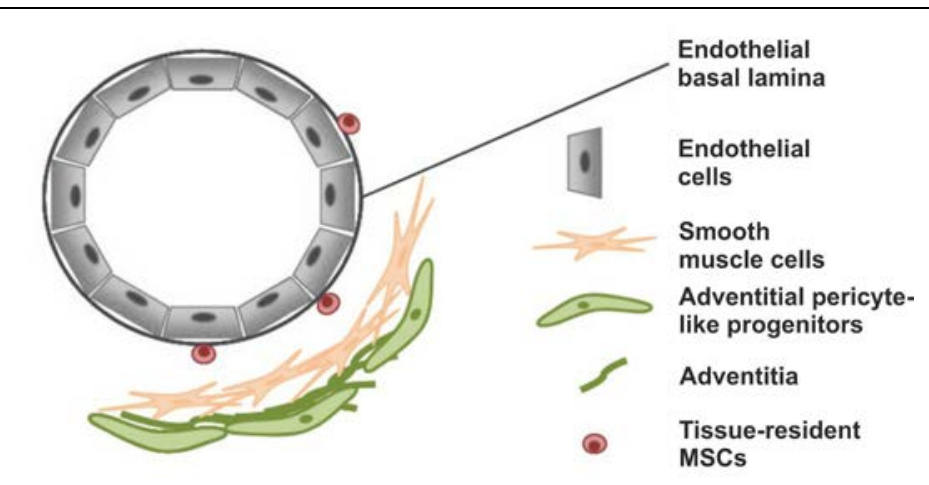

FIGURE 7 | Schematic illustration of the hypothesized location of the vascular associated MSCs (modified from IImer et al., 2014).

\subsection{Surface markers of mesenchymal stem cells cultured in serum free media}

Vascular associated MSCs can form spheroids when cultured in special serum free media (c.f. Fig. 2). In this regard it is crucial to bear in mind that only nondifferentiating MSCs are able to survive in serum free media, while the majority of progenitor cells die. Therefore, culturing cells in serum free media is a powerful tool to discriminate between true MSCs, progenitor cells and differentiated adult cells.

Figure 9 depicts the development of aggregation of human ASCs in serum free media. After four days in culture, individual cells aggregated and started to communicate with each other, as shown in Figure 9a where two cells are attached to each other (asterisk) and a third cell forms a microtubular communicating structure (arrow in Fig. 9a). A spheroid body with a diameter of approximately $300 \mu \mathrm{m}$ was formed after eight days in culture (Fig. 9b). The shape of this spheroid body resembled pretty much the shape of spheroid bodies formed by embryonic stem cells, known as embryoid bodies (e.g., Ader and Tanaka, 2014). 


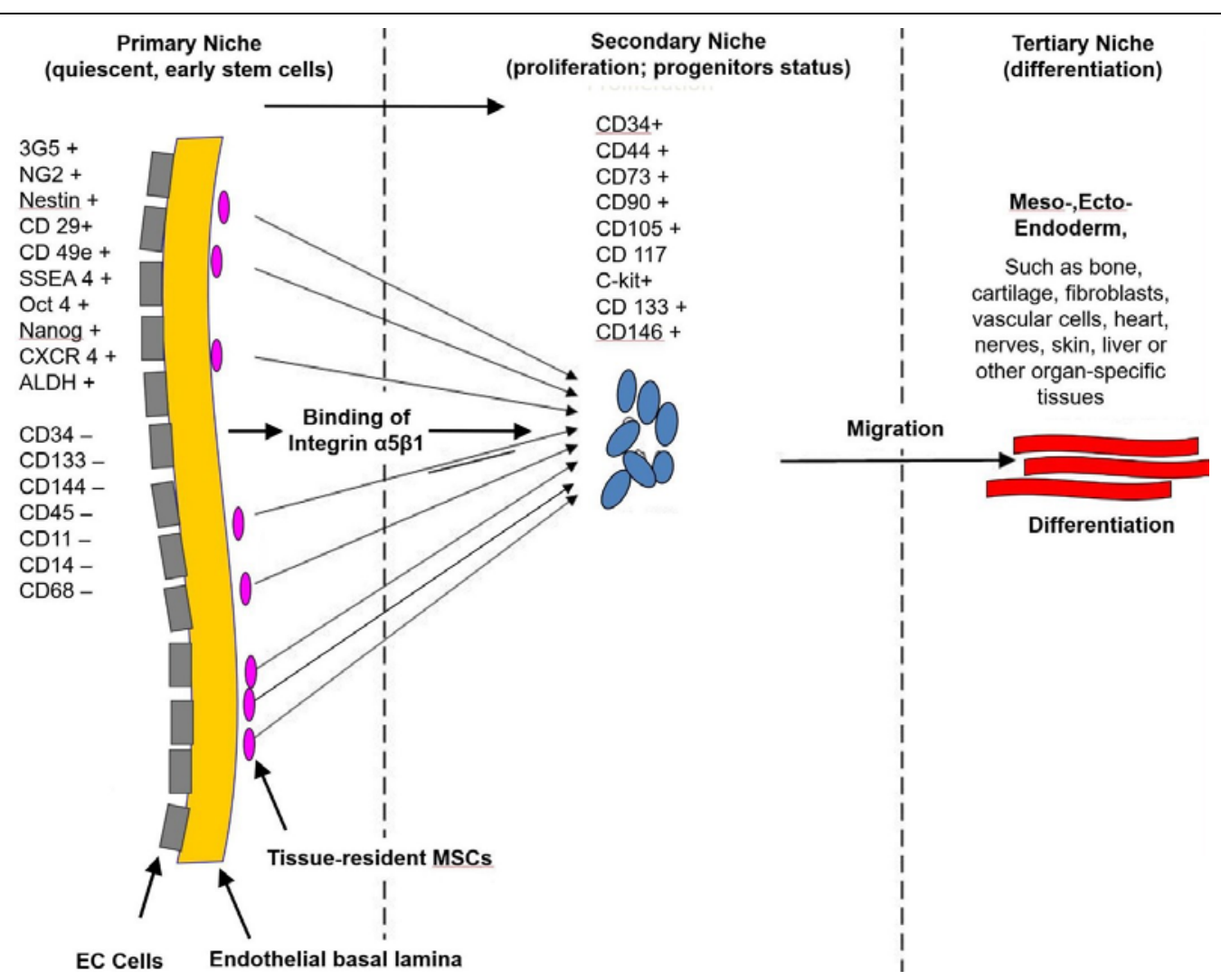

FIGURE 8 | Expression of surface markers of mesenchymal stem cells in their primary, secondary and tertiary niche.

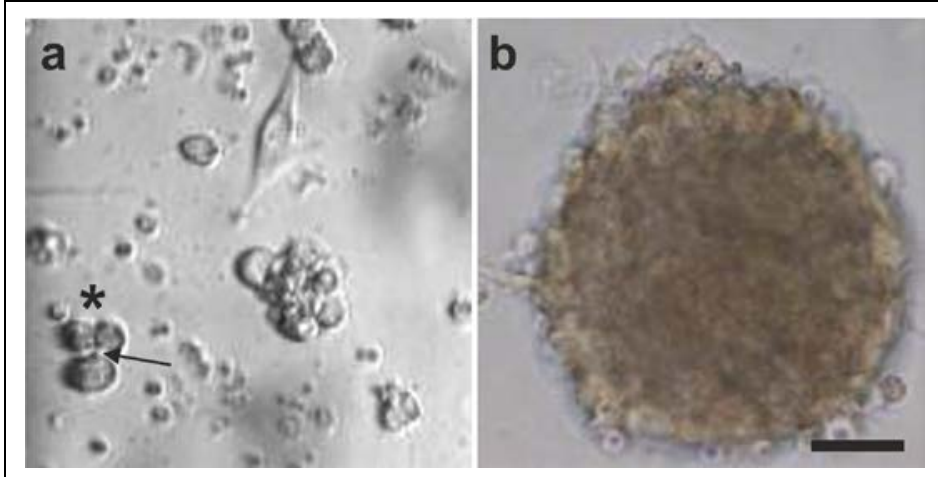

FIGURE 9 | Aggregation of human adipose-derived stem cells (a), leading to the formation of a spheroid (b) that resembles the appearance of an embryoid body formed by embryonic stem cells. The scale bar represents $20 \mu \mathrm{m}$ in (a) and $75 \mu \mathrm{m}$ in (b).

The understanding of the mode of differentiation of MSCs and their surface markers has been confusing. Specifically, markers such as CD44, CD73, CD90 and CD105 - typically believed to be indicative of true stem cells (Bourin et al., 2013) - are only present in cells that have already left their silenced location and started to enter the next developmental phase in order to attain progenitor status. Besides this, CD44, CD90 and CD105 are also expressed in fibroblasts that exhibit no plasticity at all (Alt et al., 2011).

We performed surface analysis of the antigen profiles of human ASCs that were cultured for four days in serum free media. Immunofluorescent analysis showed that these cells were immunonegative for CD11b, CD14, CD31, CD34, CD45 and HLA-DR (Fig. 10). Corresponding flow cytometric analysis revealed that the relative numbers of cells that were immunopositive for these surface markers were smaller than $1.5 \%$ (relative number of cells that were immunopositive for CD11b [CD11b+]: 1.1\%; CD14+: 0.6\%; CD31+: <0.1\%; CD34+: 0.4\%; CD45+: $1.3 \%$ and HLA-DR: $0.2 \%$ ). These results confirmed that cells that express the following markers were not present in this cell culture: macrophages (which typically are CD11b+), hematopoietic progenitor cells (CD14+), endothelial progenitor cells $(\mathrm{CD} 31+)$, progenitor cells in general (CD34+), cells expressing the pan-leukocyte marker (CD45+) and cells expressing HLA-DR. 


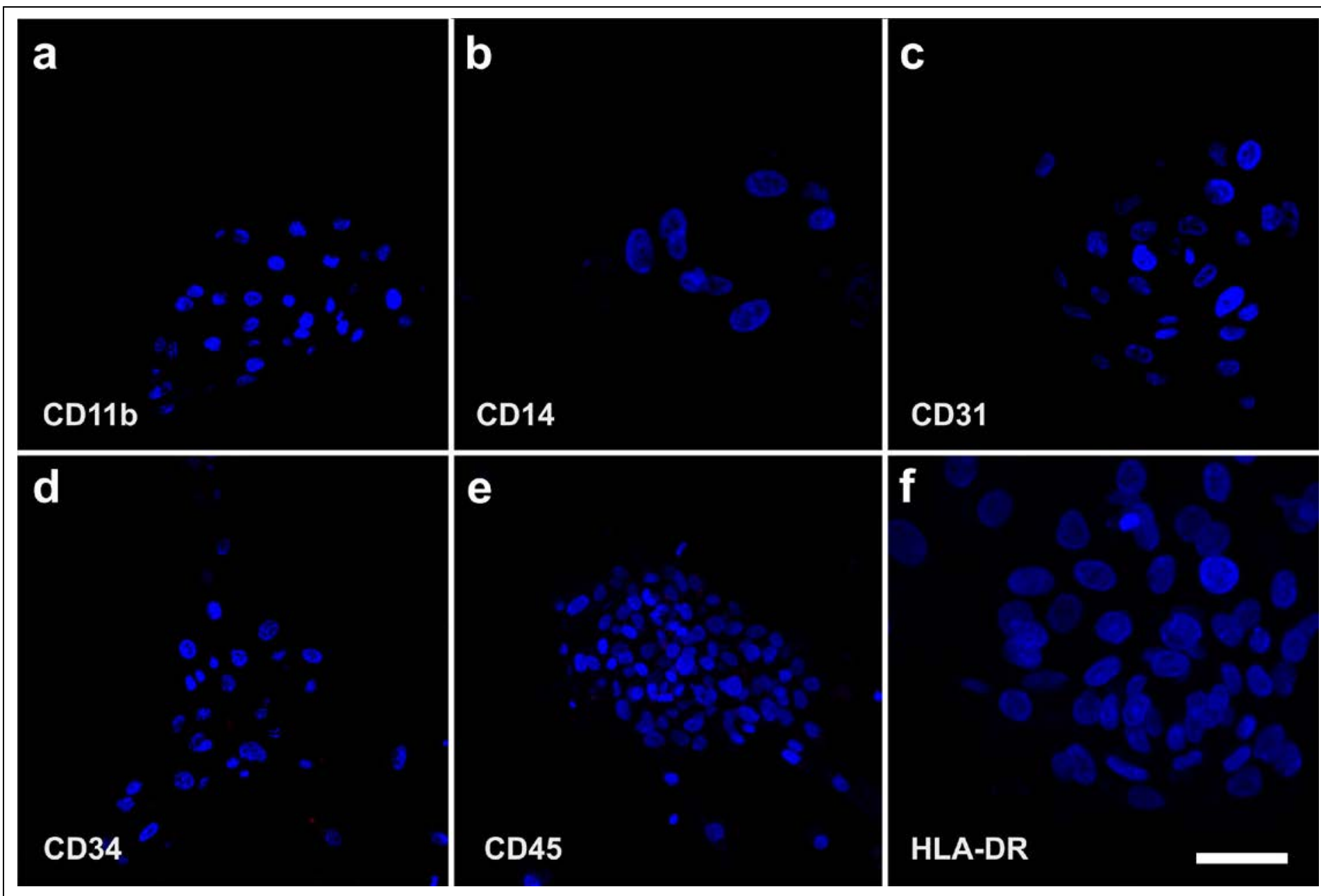

FIGURE 10 | Immunofluorescent detection of CD11b (a), CD14 (b), CD31 (c), CD34 (d), CD45 (e) and HLA-DR (f) on the surface of human adipose-derived stem cells that were cultured for four days in serum free media. The scale bar represents $60 \mu \mathrm{m}$ in (a,d,f), 20 $\mu \mathrm{m}$ in (b), $40 \mu \mathrm{m}$ in (c) and $30 \mu \mathrm{m}$ in (f).

In contrast, Figure 11 shows the positive surface marker antigen profile of human ASCs that were cultured for four days in serum free media. Immunofluorescent analysis showed that these cells were immunopositive for CD44, CD73, CD90, CD105, Nestin and SMA. Corresponding flow cytometric analysis revealed the following relative numbers of immunopositive cells in this culture: relative number of cells that were immunopositive for CD44 (CD44+): 92.4\%, CD73+: 99.1\%, CD90+: 28.8\%, CD105+: 73.3\%, Nestin+: 76.2\%, and SMA+: 41.2\%.

Most importantly, in spheroids that were created from unmodified human ASCs that were cultured for four days in serum free media, cells expressed both Oct4 as an indicator of 'stemness' as well as NG2. This clearly indicates the natural presence of pluripotent cells in the body without the need for prior genetical modification of the cells as in case of iPS cells (Fig. 12).

For the sake of completeness it should be mentioned that the results shown in Figs. 10-12 critically depend on the time and mode of culturing. We demonstrated this by culturing human ASCs in serum free media and analyzed the cells after 24 hours and again after 120 hours. After 24 hours in culture, the relative numbers of CD11b+, CD34+, CD45+ and CD105+ cells were 10.0\%, 48.1\%, 6.1\% and $50.1 \%$. In contrast, after 120 hours in culture the relative numbers of CD11b+, CD34+ and CD45+ cells dropped to less than 2\%, whereas the relative number of CD105+ cells increased to $96.7 \%$. We hypothesize that in culture the loss of the CD34 surface marker as indicator of progenitor status is a consequence of missing signaling from the normally surrounding microenvironment in the natural tissue.

\subsection{The pluripotency of vascular associated mesenchymal stem cell}

It has been questioned whether a truly pluripotent stem cell exists, or if the differentiation into the three germ layers is based on the presence of a composition of different progenitor cells that are responsible for the individual differentiation capacity into the respective lineage. To answer this question, we performed two key 
experiments.

In the first experiment a single vascular associated mesenchymal stem cell was clonally expanded for five days in FBS, resulting in proliferation at a doubling time of about 24 hours into millions of cells (Fig. 13a-d). Then, cells were separated from this clonally expanded culture and subjected to adipogenic, osteogenic, hepatogenic and neurogenic induction media. It was found that the clonally expanded cells, which all expressed the same genotypic profile, were able to differentiate into ectoderm, mesoderm and endoderm (Fig. 13e-h), indicating that the initial single cell was indeed a true pluripotent stem cell.

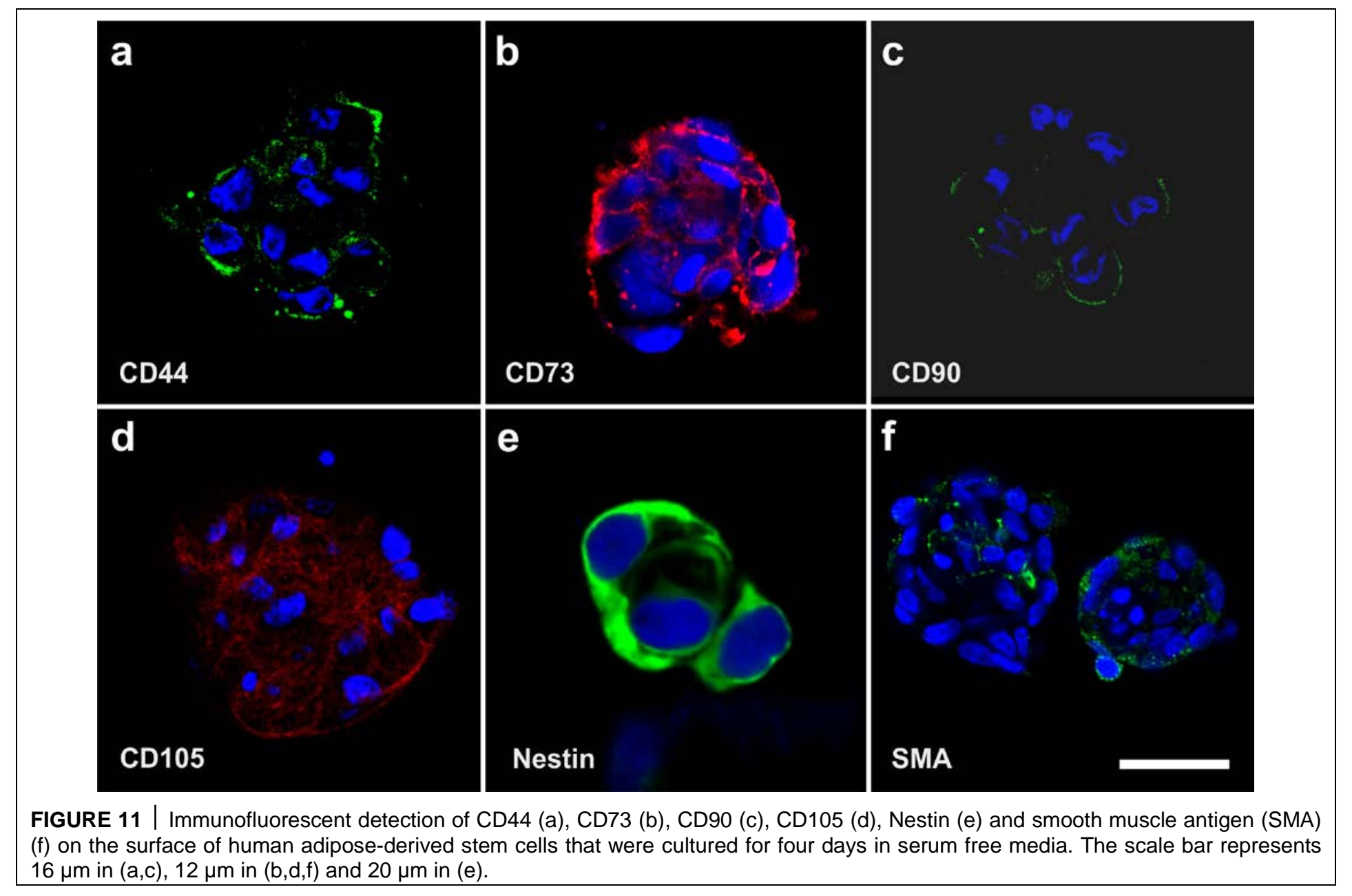

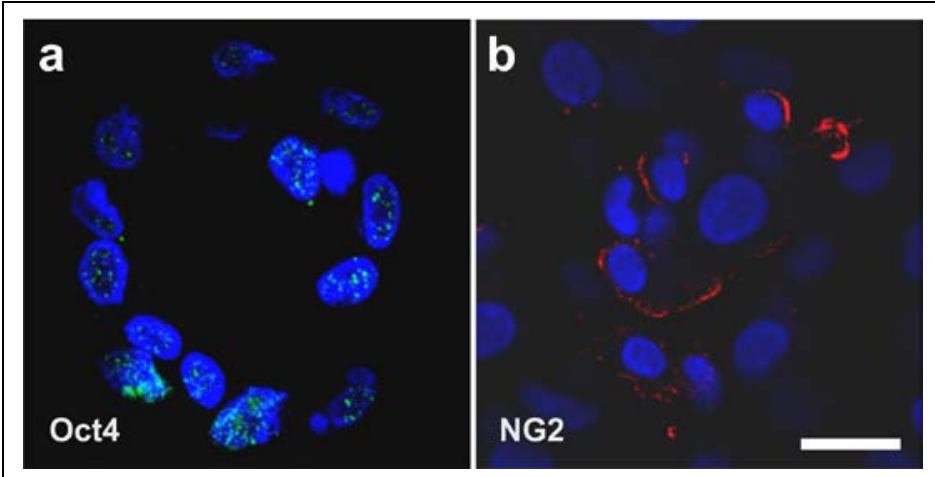

FIGURE 12 Immunofluorescent detection of Oct4 (a) and neuron-glial antigen 2 (NG2) (b) in cells in spheroids that were created by unmodified human adipose-derived stem cells that were cultured for four days in serum free media. The scale bar represents $20 \mu \mathrm{m}$.
In the second experiment we isolated vascular associated MSCs from different organs (adipose tissue, heart, skin, bone marrow and skeletal muscle) of rats and subjected them after proliferation in FBS to adipogenic, osteogenic, hepatogenic and neurogenic induction media. Again, the cells were able to differentiate into ectoderm, mesoderm and endoderm (Fig. 14).

The results of these key experiments provide significant support for the hypothesis of a universal, vascular associated mesenchymal stem cell with full pluripotency. 


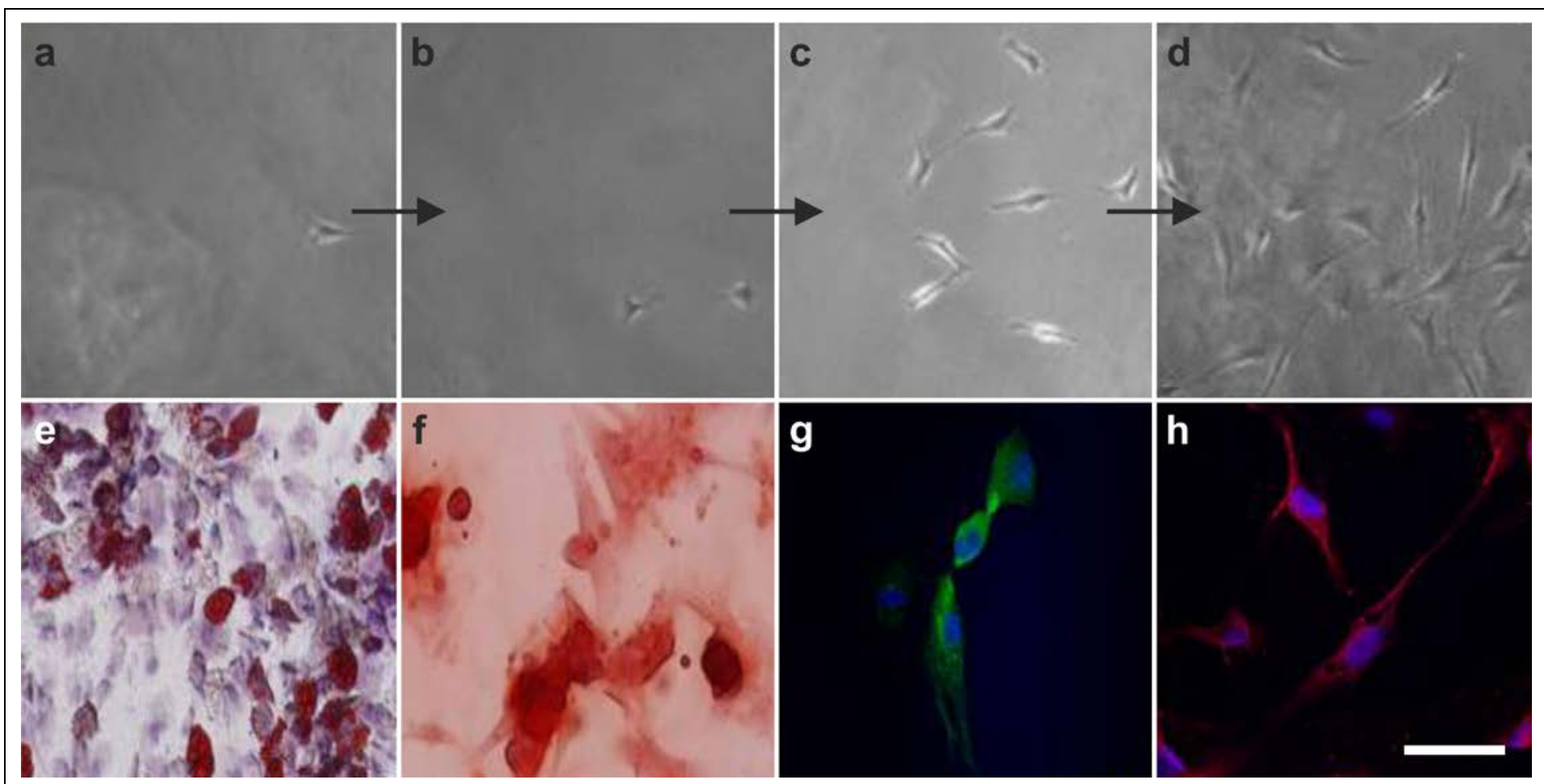

FIGURE 13 | Clonal expansion of vascular associated human adipose-derived stem cells for five days in fetal bovine serum (FBS), followed by multilineage differentiation induced by culturing the cells for three weeks in the respective induction media. (a-d) Culturing of cells in FBS for 6 hours (a), 20 hours (b), 48 hours (c) and five days (d). (e-h) Induction of adipogenesis (mesoderm) (e), osteogenesis (mesoderm) (f), hepatogenesis (endoderm) (g) and neurogenesis (ectoderm) (h), confirmed by Oil Red O staining (e) and Alizarin Red S staining (f) as well as immunofluorescent detection of albumin (specific for hepatocytes) (g) and microtubule associated protein 2 (MAP-2) (specific for neurons) (h). The scale bar represents $80 \mu \mathrm{m}$ in (a-d), $100 \mu \mathrm{m}$ in (e,f) and $40 \mu \mathrm{m}$ in (g,h).

\subsection{The three germ layer differentiation potential of human adipose-derived stem cells}

In 2007, we initially demonstrated the three germ layer differentiation potential of human ASCs into adipocytes, osteoblasts, hepatocytes and neurons (Bai et al., 2007). While the cells cultured in non-inductive media did not attain the lineage specific expression, cells subjected to the specific induction media demonstrated the respective differentiation (Fig. 15).

\subsection{Regulation of the differentiation of stem cells in a living organism}

The first experiments we conducted in this regard were carried out to highlight the possible influence of the microenvironment surrounding the cells. This involved co-culturing of neonatal rat cardiomyocytes with human ASCs. In order to discriminate between the two different types of cells, we labeled the human ASCs with green fluorescent protein (GFP). Figure 16a shows a cell that is immunopositive for the cardiac specific protein Troponin$\mathrm{T}$ (red signal). Figure 16b shows GFP (green signal) in the cytosol of human ASCs. One cell shows a yellowish cell body (arrow) that was obtained by the overlay of the green signal (GFP) with a red signal originating from immunofluorescent detection of MF20, one of the early markers of the cardio-myogenic pathway differentiation (c.f., e.g., Belema Bedada et al., 2005). In contrast, ASCs that were not co-cultured with rat cardiomyocytes did not show this early cardio-myogenic pathway differentiation.

Figure 17 shows a direct cell-cell contact between a rat cardiomyocyte (identified by immunofluorescent detection of Troponin-T; red signal) and a cell that expressed both GFP and Troponin-T (yellowish signal). The latter represents a human ASC at the latest stage of culturing. At higher magnification (inset in Fig. 17) it appears that the two cells adhered to each other, and reddish microchannels appear to run from one cell to the other, indicating a possible microchannel communication for the exchange of information.

We further investigated the exchange of information between ASCs and other cells by time-lapse video microscopy of human ASCs that were labeled with red Quantum dots (e.g., Yukawa et al., 2009) and were cocultured with MDA-MB-231 cells (a commercially available human breast cancer cell line; c.f., e.g., Brinkley et al., 1980) that were labeled with GFP (Fig. 18). In our opinion the communication mechanism between cells 
found in this experiment is the same as the cell-cell connection of endothelial progenitor cells with cardiac myocytes by nanotubes described by Koyanagi et al. (2005) as an important mechanism for cell fate changes.

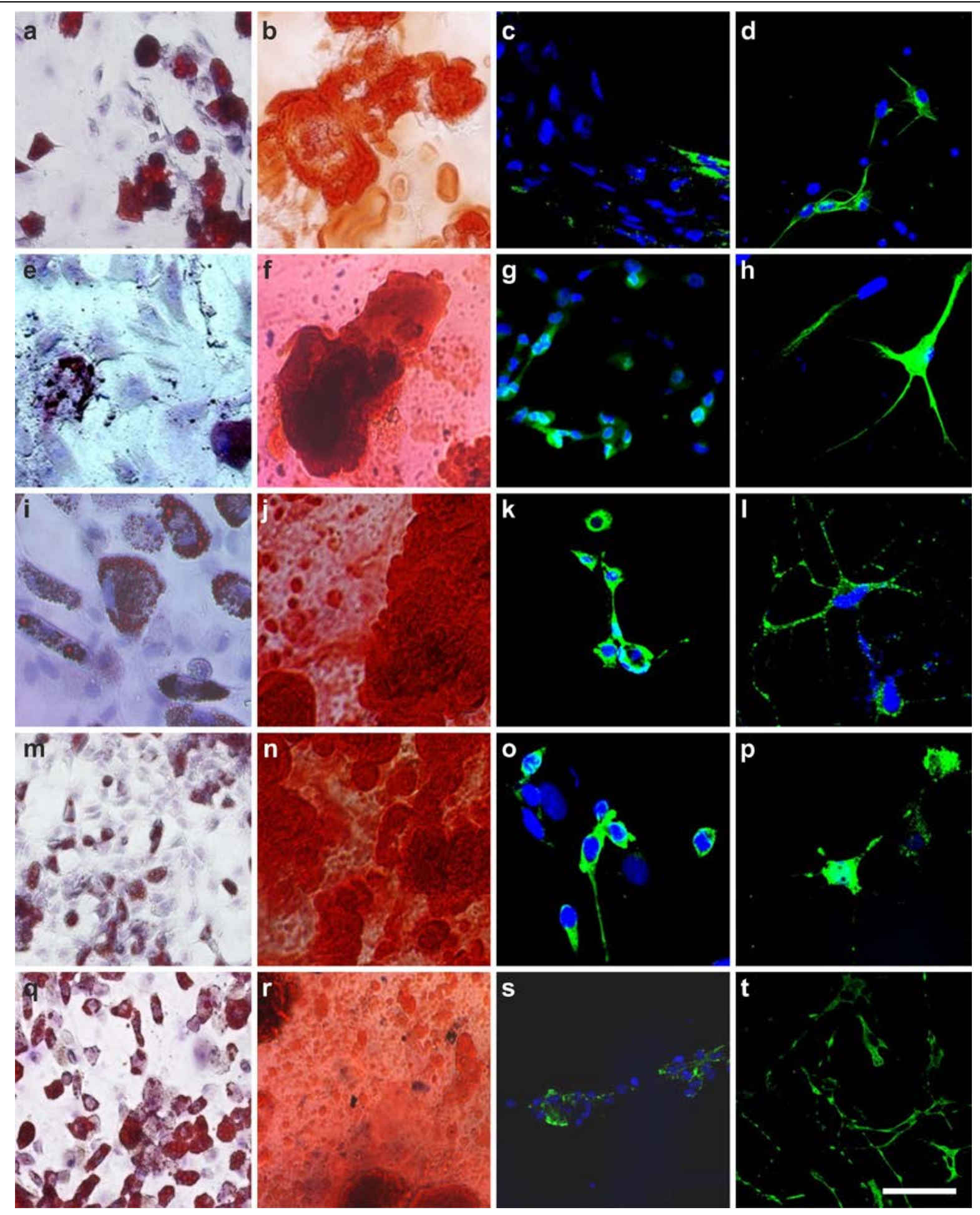

FIGURE 14 | Induction of adipogenesis (mesoderm; confirmed by Oil Red O staining) (a,e,i,m,q), osteogenesis (mesoderm; confirmed by Alizarin Red S staining) (b,f,j,n,r), hepatogenesis (endoderm; confirmed by immunofluorescent detection of albumin) (c,g,k,o,s) and neurogenesis (ectoderm; confirmed by immunofluorescent detection of MAP-2) (d,h,l,p,t) by culturing rat vascular associated mesenchymal stem cells obtained from adipose tissue (a-d), heart (e-h), skin (i-l), bone marrow (m-p) and skeletal muscle (q-t) for three weeks in the respective induction media. The scale bar represents $100 \mu \mathrm{m}$ in (a,e,m,q), $120 \mu \mathrm{m}$ in (b), $50 \mu \mathrm{m}$ in (c,d,f-h,j,n,r), $20 \mu \mathrm{m}$ in (i), $70 \mu \mathrm{m}$ in (k), $30 \mu \mathrm{m}$ in (l,p), $25 \mu \mathrm{m}$ in (o) and $60 \mu \mathrm{m}$ in (s,t). 


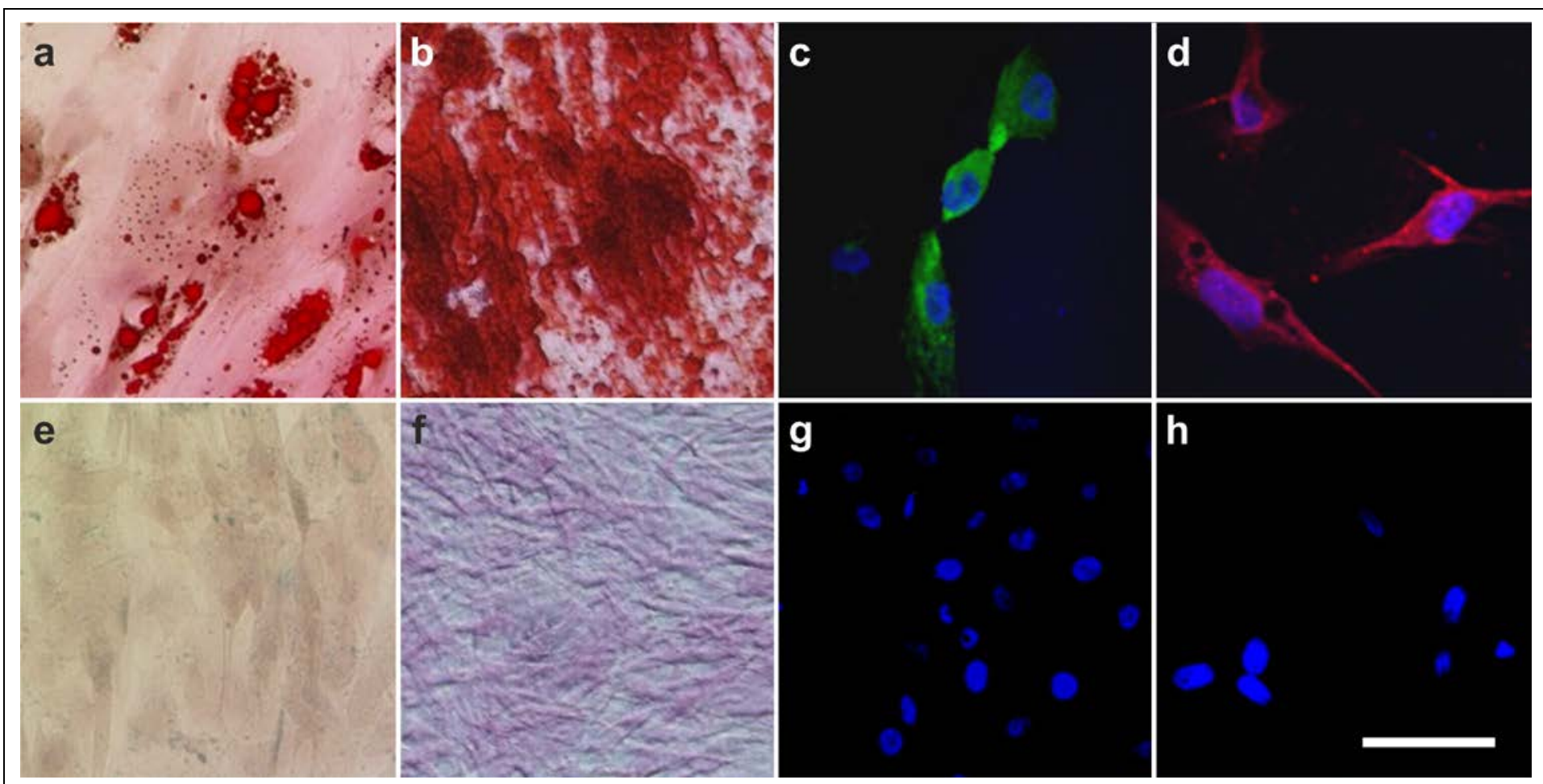

FIGURE 15 | Induction of adipogenesis (mesoderm; confirmed by Oil Red O staining) (a), osteogenesis (mesoderm; confirmed by Alizarin Red S staining) (b), hepatogenesis (endoderm; confirmed by immunofluorescent detection of albumin) (c) and neurogenesis (ectoderm; confirmed by immunofluorescent detection of MAP-2) (d) by culturing human adipose-derived stem cells (ASCs) for three weeks in the respective induction media. (e-h) No induction of three germ layer differentiation by culturing human ASCs in non-inductive control media. The scale bar represents $100 \mu \mathrm{m}$ in $(\mathrm{a}, \mathrm{b}, \mathrm{e}, \mathrm{f})$ and $40 \mu \mathrm{m}$ in $(\mathrm{c}, \mathrm{d}, \mathrm{g}, \mathrm{h})$.
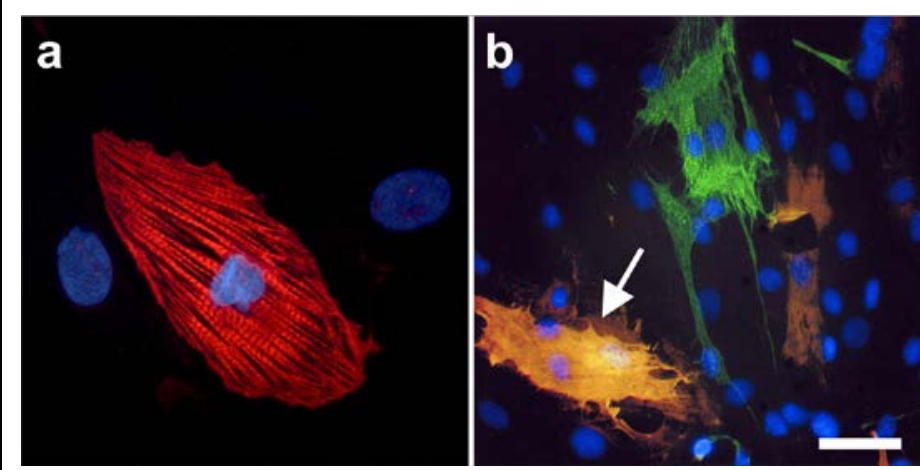

FIGURE 16 | (a) Immunofluorescent detection of Troponin-T in the cytoplasm of a rat cardiomyocyte (red signal). (b) Human adipose-derived stem cells that were labeled with green fluorescent protein (GFP) (green signal). The arrow points to a GFP-positive cell that was immunopositive for MF20 (resulting in a yellowish signal). The scale bar represents $20 \mu \mathrm{m}$ in (a) and 40 $\mu \mathrm{m}$ in (b).

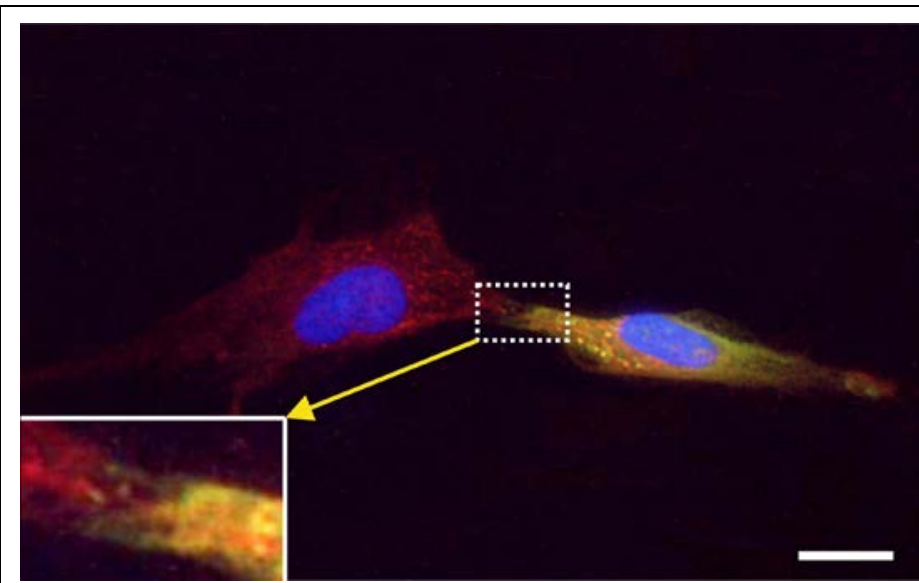

FIGURE 17 | Cell-cell contact between a rat cardiomyocyte (expressing Troponin-T; red signal) and a cell expressing both green fluorescent protein and Troponin-T (yellowish signal), representing a human adipose-derived stem cell at the latest stage of culturing (modified from Metzele et al., 2011). The inset shows the contact between the cells at higher magnification. The scale bar represents $15 \mu \mathrm{m}$ (5 $\mu \mathrm{m}$ in the inset). 


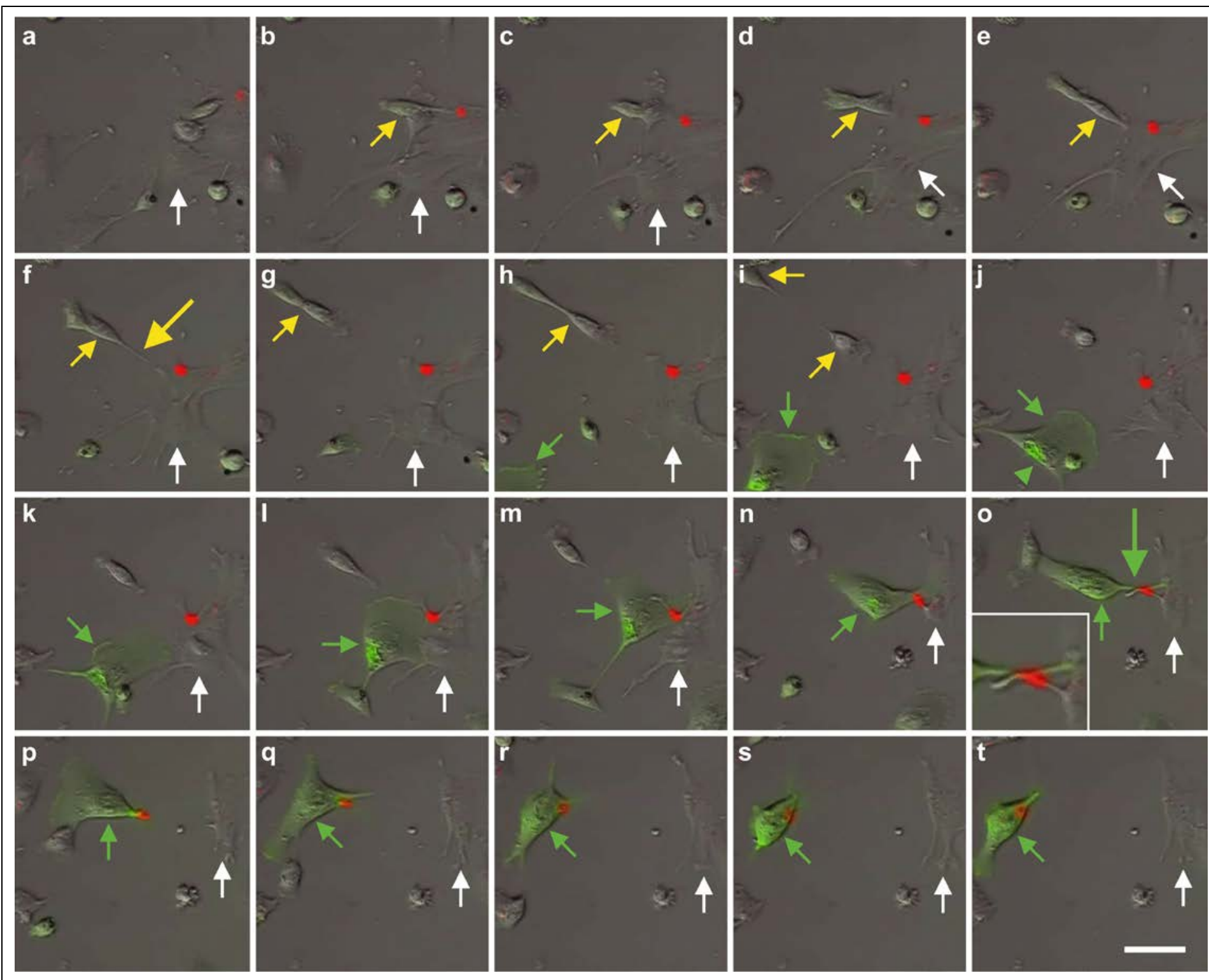

FIGURE 18 | Time-lapse video microscopy of human adipose-derived stem cells (ASCs) that were co-cultured with MDA-MB-231 cells labeled with green fluorescent protein (GFP) (green signal). One of the ASCs shown in this figure was labeled with a red Quantum dot (red signal; the corresponding cell body is marked by a white arrow). In (f) this ASC formed a contact with another ASC (yellow arrows; the cell-cell contact is indicated by the large yellow arrow in f). However, the Quantum dot was not exchanged between the cells. In (o) the same ASC formed a contact with a MDA-MB-231 cell (green arrows; the cell-cell contact is indicated by the large green arrow in o) and the Quantum dot was transferred from the ASC to the MDA-MB-231 cell. The high-power inset in o shows that the Quantum dot left the ASC through a microchannel that was formed by the ASC itself, which demonstrates active participation of the ASC in exchange of cellular components between the cells. The time interval between the frames was 40 min each. The scale bar represents $50 \mu \mathrm{m}$ in a-t, and 25 in the inset in 0.

A second type of cell-cell communication is based on genetic information contained in the exosomes (or microsomes), which are released from the cell surface (c.f. the inset in Fig. 4) and, upon uptake by pinocytosis (Fig. 19), induce a certain epigenetic reprogramming in the recipient cell (e.g., Valadi et al., 2007; Xin et al., 2012; Ismail et al., 2013). These exosomes are currently of major interest with respect to further elucidating cell-cell communication (e.g., Kruger et al., 2014). Specifically, communication through the content of exosomes is considered an important factor for orientation of cells (Xu et al., 2017). Several micro-RNAs, transcription factors and cytokines were identified to be involved in the transfer of epigenetic reprogramming of cells in order to direct them into a specific lineage differentiation. It was also shown recently that microsomes obtained from a murine pancreatic $\beta$-cell line are able to induce a beta cell differentiation of bone marrow derived MSCs (Oh et al., 
2015), further supporting the notion that the orientation and differentiation of MSCs are driven by signals of the respective microenvironment (c.f. Valadi et al., 2007; Ismail et al., 2013; Yamamoto et al., 2013).

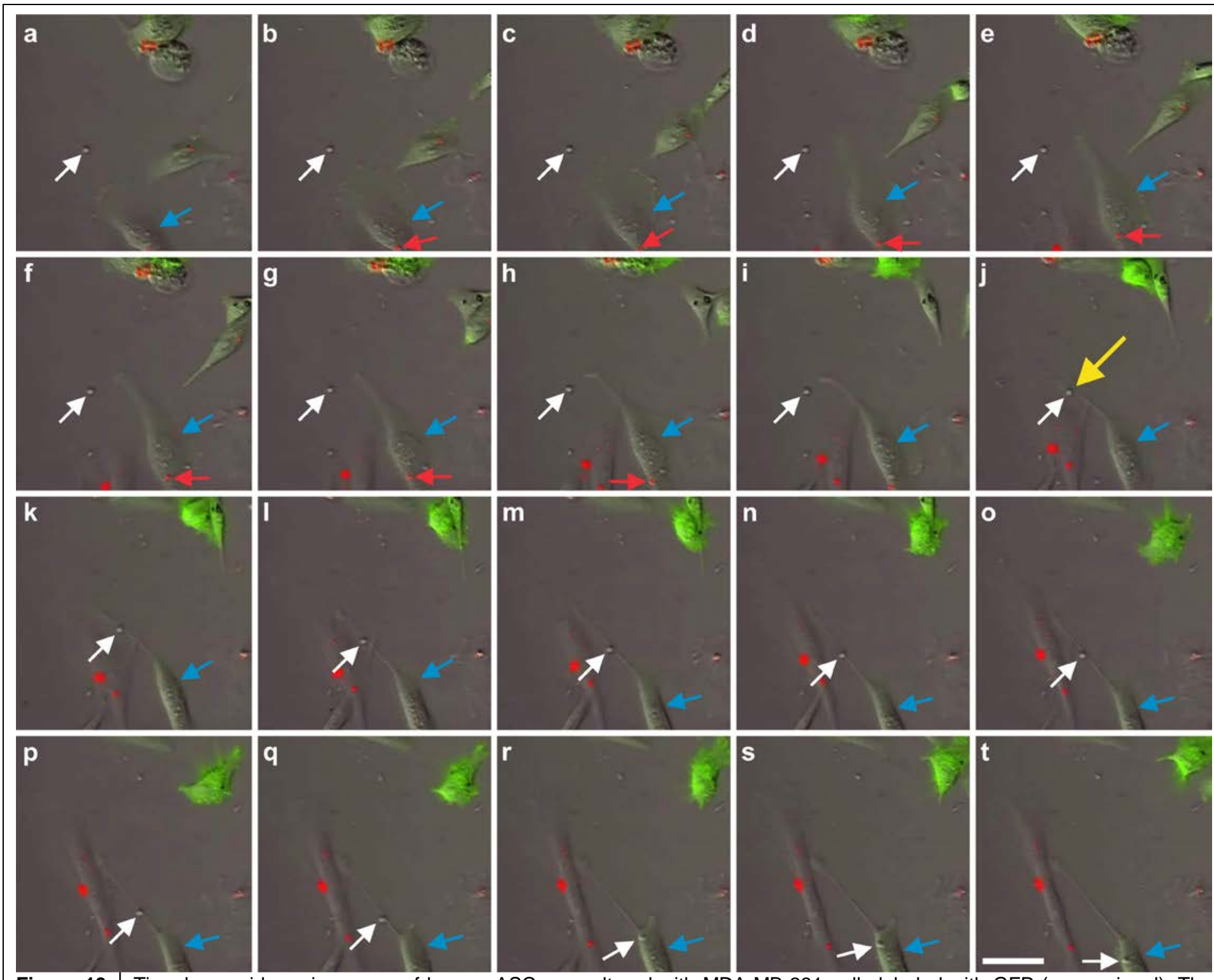

Figure 19 Time-lapse video microscopy of human ASCs co-cultured with MDA-MB-231 cells labeled with GFP (green signal). The ASCs were labeled with red Quantum dots (red signal). A Quantum dot in the cell body of one of the ASCs is marked by a red arrow in (b-h); the corresponding cell is marked by a green arrow. The white arrows point to an exosome. The yellow arrow in (j) indicates the event of pinocytosis of this exosome by the ASC that is marked by the green arrow. The time interval between the frames was 20 min each. The scale bar in (t) represents $50 \mu \mathrm{m}$.

\subsection{Immunosuppressive and anti-inflammatory activities of stem cells}

Both ASCs and bone marrow derived MSCs exhibit potent immunosuppressive and anti-inflammatory activities (c.f., e.g., Krampera et al., 2003; González et al., 2009; Leto Barone et al., 2013), and exosomes were shown to play an important role in these processes (Caruso and Poon, 2018). In recent years apoptotic bodies, a major class of extracellular vesicles released as a product of apoptotic cell disassembly, have become recognized as another key player in immune modulation (Caruso and Poon, 2018). A recent study demonstrated that apoptosis in human bone marrow derived MSCs induces recipient-mediated immunomodulation in vivo (Galleu et al., 2017). On the other hand, even in tissues with high cellular turnover, apoptotic cells are rarely seen because of efficient clearance mechanisms, including the sensing of cells that undergo apoptosis via 'find me' signals (i.e., chemotactic factors) (c.f., e.g., Hochreiter-Hufford and Ravichandran, 2013). One of these chemotactic factors is the 
phospholipid, lysophosphatidylcholine (Lauber et al., 2003). Increased concentration of lysophosphatidylcholine was found in the medium in which hematopoietic progenitor cells underwent apoptosis following growth factor withdrawal (Fuchs et al., 2007). Our time-lapse video microscopic investigations showed that human ASCs that undergo apoptosis also stimulate the migration of other cells to the apoptotic cell, and these other cells can then take up the apoptotic bodies via pinocytosis (Fig. 20). However, it is currently unknown which 'find me' signals are used by ASCs that undergo apoptosis. In any case, apoptosis of ASCs may be a key event in immunosuppressive and anti-inflammatory activities mediated by these cells.

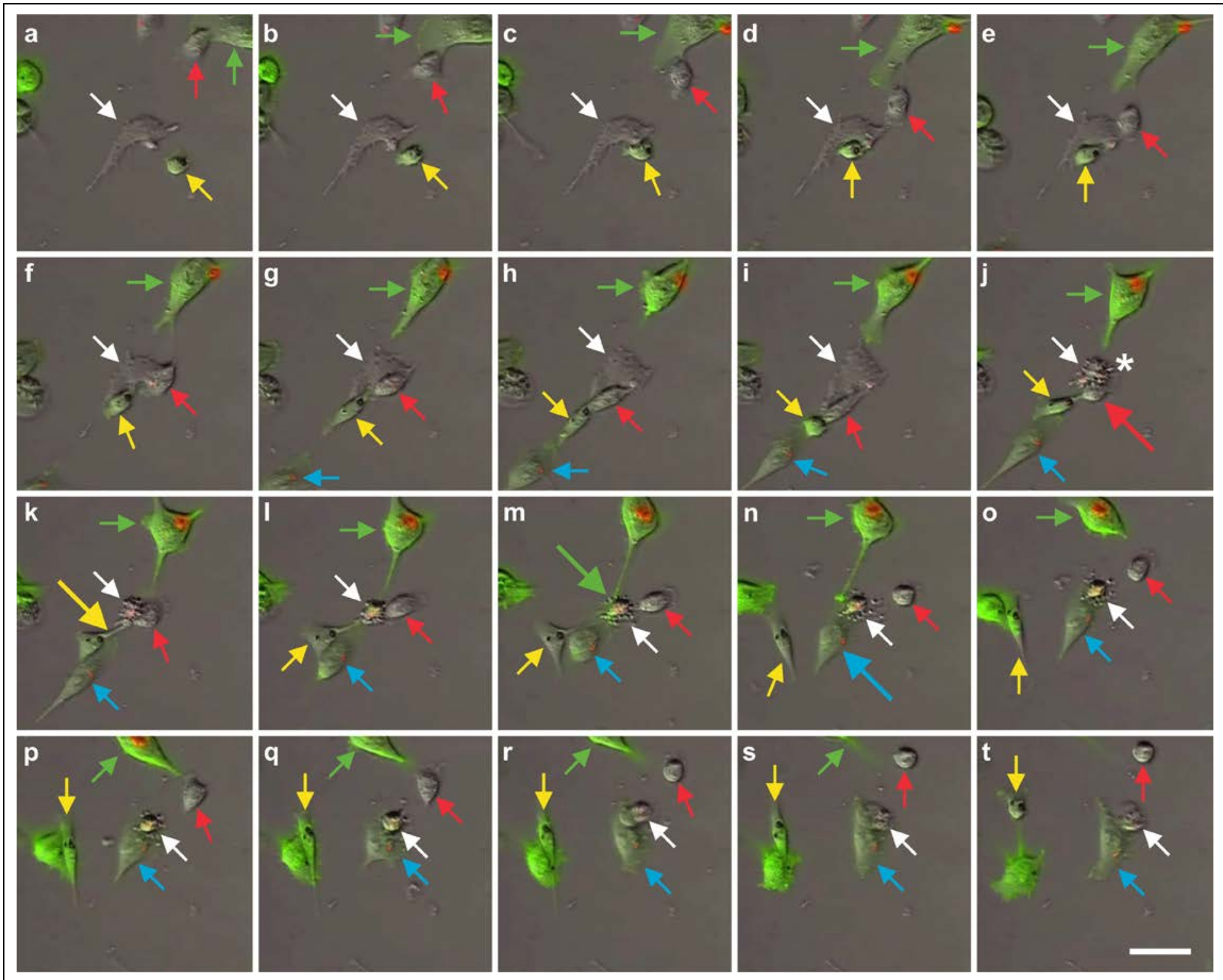

FIGURE 20 | Time-lapse video microscopy of human adipose-derived stem cells (ASCs) that were co-cultured with MDA-MB-231 cells labeled with green fluorescent protein (GFP) (green signal; the red signal came from red Quantum dots that were exchanged between the ASCs and the MDA-MB-231 cells (c.f. Fig. 18). The white arrow indicates an ASC that underwent apoptosis (named Cell A; the disintegration of the cell body is marked in $\mathrm{j}$ by an asterisk). The red, yellow, green and blue arrows indicate four other cells (named Cells B-E) that migrated towards Cell A during the three hours before disintegration of the cell body of Cell A (a-i). One of these cells was an ASC (red arrows) whereas the other three cells were MDA-MB-231 cells. During the first 90 min after disintegration of the cell body of Cell A, Cells B-E took up apoptotic bodies of Cell A by means of pinocytosis (indicated by larger arrows in the respective colors in $\mathrm{j}, \mathrm{k}, \mathrm{m}, \mathrm{n})$. The time interval between the frames was 20 min each. The scale bar in (t) represents $50 \mu \mathrm{m}$. 


\subsection{A key role of stem cell therapy in re- establishing tissue homeostasis between dying and replacing cells}

A key function of adult stem cells is to contribute to the homeostasis of tissue resident parenchymal cells. As we age, there is a continuous turnover in almost every tissue between dying and replacing cells (with the exception of some nerve cells in the brain, which will not be discussed in detail here; c.f., e.g., Rakic, 1985; Breunig et al., 2007; Jellinger and Attems, 2013). For a long time our body can maintain tissue homeostasis; the equilibrium between dying cells and stem cells is depicted in Figure 21a.

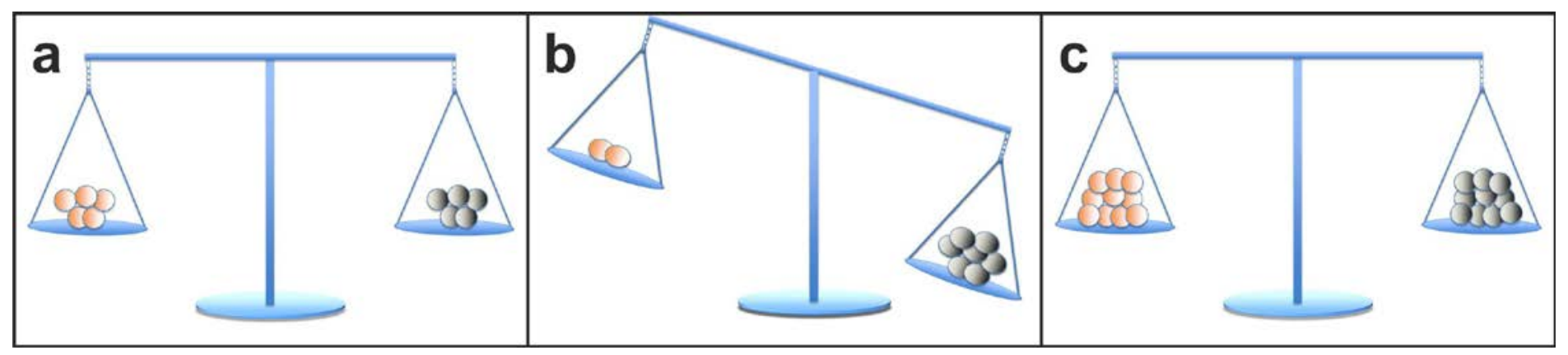

FIGURE 21 | Homeostasis between dying cells (gray) and stem cells (orange) in tissue under healthy conditions (a), the situation under pathological conditions and during aging (b), and after stem cell therapy (c). Under healthy conditions, tissue homeostasis is maintained between dying cells and replacing stem cells. In contrast, tissue homeostasis is disrupted under pathological conditions and during aging as more cells are dying than being replaced by stem cells. Application of a concentrated stem cell preparation can reestablish tissue homeostasis.

However, tissue homeostasis can be disturbed with increasing age in all tissues, such as tendons, bone, joints, heart, liver, kidneys and muscles in a way that the parenchymal cells, which are responsible for the organ function, are more and more replaced by mesenchymal fibroblastic cells. This is due to a lack of renewing power, especially if ischemia, infections, accidents and other inflammatory or traumatic events accelerate the tissue turnover (Fig. 21b). A good example are chronic wounds that show a number of problems, including insufficient levels of cell proliferation, increased cell senescence/apoptosis, impaired angiogenesis/neovascularization, inflammation, increased production of matrix metalloproteinases, increased matrix degradation and decreased production of extracellular matrix (c.f., e.g., Demidova-Rice, Hamblin and Herman, 2012).

An important question that has remained in this regard is why injured organs (for example, a heart after a myocardial infarction) do not source the stem cells from a part of the body where they are present and would not be 'missed' after recruitment (such as from adipose tissue). It is currently not possible to provide a satisfactory answer to this question, because it would require to analyze model organisms in which spontaneous recruitment of stem cells from parts of the body where they are present and would not be 'missed' after recruitment would occur. To our knowledge, such model organisms are not known. Several animal models for the study of limb regeneration have been described, among them the Mexican axolotl (Ambystoma mexicanum) (c.f., e.g., McCusker and Gardiner, 2011; Farah et al., 2016; Grillo, Konstantinides and Averof, 2016). It turned out that in limb regeneration, a morphologically uniform intermediate (the so-called blastema) is formed, consisting of a variety of multipotent stem and progenitor cells originating from a variety of tissues (Zielins et al., 2016). Further deciphering the genetic and molecular regeneration inducers that are involved in limb regeneration (Satoh, Mitogawa and Makanae, 2015; Haas and Whited, 2017) may serve as the basis to understand which signals could in general be used by injured organs to recover stem cells from parts of the body where they are not 'missed' after recruitment, followed by investigations into why this does not happen in the human body. In any case, the distance between the stem cells in these parts of the body where they would not be 'missed' after recruitment (as in adipose tissue) and those cells that 'call' for the stem cells by the release of cytokines may simply be too long.

Stem cell therapy is to be considered as the principal of transferring concentrated stem cells, which have been taken from one part of the body where they are not 'missed', to tissue in need of regeneration in order to reestablish tissue homeostasis (Figure 21c). The isolation of stem cells from suitable tissue (such as adipose tissue) and their application to other injured tissue and organs can be interpreted as the most gentle approach to help the body in self-repair by increasing the numbers of stem cells at a 
location where they are most needed. From these considerations it also becomes clear that stem cell therapy is not only directed to a specific organ, tissue or disease, but will take the function of replacing and repairing tissue and organs that suffer from a lack of repair, renewal and rejuvenation.

\section{Key advantages of adipose-derived regenerative cells over bone marrow derived stem cells for cell based therapies}

\subsection{Comparison of bone marrow derived stem cells with adipose-derived stem cells}

For almost a decade bone marrow was the primary source of MSCs for research into and development of therapies based on adult stem cells. Bone marrow derived MSCs exhibit significant potential for promoting tissue regeneration, protection of ischemic tissue at risk, and modulation of inflammation and autoimmunity (Murphy, Moncivais and Caplan, 2013). However, utilizing bone marrow derived MSCs for therapeutic purposes typically requires to first isolate these cells and expand them in culture. Because of the overwhelming presence of hematopoietic progenitor cells in bone marrow that aim to form new blood cells (Al-Drees et al., 2015; Ratajczak, 2015), only a small fraction of the cells in fresh bone marrow aspirate are true pluripotent stem cells. In contrast, other tissues such as adipose tissue yield orders of magnitude more MSCs per unit volume than bone marrow (e.g., Izadpanah et al., 2006; Yoshimura et al., 2006; Bruno et al., 2014). In fact, as highlighted in the previous sections of this article, adipose tissue is an organ that is highly vascularized and contains a significant number of MSCs. Thus, adipose tissue may be utilized as a fresh cell preparation, rich in MSCs, without the need for expansion in cell culture. There is also less damage to the tissue where the stem cells are taken from, and typically, the stem cells in adipose tissue have not been challenged by ischemia, trauma or infections.

Compared to other sources of adult stem cells, adipose tissue has the following specific advantages: (i) adipose tissue is readily available in most individuals; (ii) small amounts of adipose tissue ( 25 to $100 \mathrm{ml}$ ) can be harvested using a simple liposuction procedure with low invasiveness, with tolerable discomfort and low donor-site damage; (iii) considerably larger amounts of MSCs can be obtained from adipose tissue than from the same amount of bone marrow; and (iv) the latter allows the usage of ASCs without further need of culturing (named adiposederived regenerative cells [ADRCs] in order to differentiate from cultured ASCs; c.f. Fig. 1). Given these advantages, unmodified, autologous ADRCs (UAADRCs) appear to be the most promising candidate for repair and regeneration of many tissues, including chronic wounds, soft tissue defects, bone and cartilage defects, non-healing fractures, tendinopathies, diseased or injured myocardium, urological conditions such as incontinence, and neurological conditions (c.f., e.g., Schäffler and Büchler, 2007; Gimble, Guilak and Bunnell, 2010; Altman et al., 2010; Alt et al., 2011; Gir et al., 2012; Klein et al., 2016).

\subsection{Differences in the effectiveness of various systems and methods that are available for isolating adipose-derived regenerative cells}

Different techniques and protocols were described for releasing ADRCs for therapeutic use (c.f., e.g., Oberbauer et al., 2015; Condé-Green et al., 2016; Van Dongen et al., 2018). Collagenase I and II containing enzyme preparations that degrade collagen are commonly used. However, in order to release the vascular associated MSCs from their binding site in the extracellular matrix inside the blood vessels (and hereby to release the cells from their 'hibernating' or silenced state) collagenases are only partially effective. The addition of a neutral protease to a collagenase enzyme preparation can significantly increase the number of ADRCs recovered from a given volume of adipose tissue. This was achieved by developing the proprietary Matrase enzymatic reagent (InGeneron Inc., Houston, TX, USA). Isolating ADRCs with the Matrase enzymatic reagent and the Transpose RT system (InGeneron) appears advantagous to other commercial cell separation systems (c.f. Haenel et al., 2018). Specifically, ADRCs that were isolated with the Matrase enzymatic reagent and the Transpose RT system may contain approximately $40 \%$ of cells that are immunopositive for CD29 and CD44, which are markers of ASCs (Haenel et al., 2018). These authors also reported a colony forming units (CFU) frequency (considered to be an indicator of stemness) of approximately $11 \%$ of ADRCs isolated with the Matrase enzymatic reagent and the Transpose RT system. Metcalf et al. (2016) reported relative CFU values of approximately $8 \%$ when isolating ADRCs from equine adipose tissue. In contrast, relative CFU values between $0.2 \%$ and $1.7 \%$ were reported for ADRCs that were isolated in head-to-head comparisons with four other commercial cell separation systems (Aronowitz \& Ellenhorn, 2013; Aronowitz et al., 2016). However, a direct comparison of the CFU values is hardly possible due to significant methodological differences how the respective numbers of CFUs were determined. 


\subsection{Long-term survival of adipose-derived stem cells after transplantation in animal models into the heart and subcutaneous locations}

In order to study the capacity of ASCs to survive for a long time at the site of engraftment, we transfected human ASCs with a lentiviral vector expressing GFP and luciferase (when the luciferase enzyme is expressed in living cells, these cells are capable of converting systemically injected luciferin dye into an active luminescent fluorophor that can be detected noninvasively; e.g., de Almeida, van Rappard and $\mathrm{Wu}$, 2011; Scarfe et al., 2017). Figures 22 and 23 show the time course of luciferin positive human ASCs that were either intramyocardially delivered into severe combined immunodeficient (SCID) mice after experimental induction of myocardial infarction by permanent ligation of the left anterior descending coronary artery (Fig. 22), or into a subcutaneous location of SCID mice (Fig. 23), respectively. Strong bioluminescence signals were found over the injection sites at all investigated time points (indicated in Figs 22 and 23), demonstrating the long-term survival of ASCs delivered into injured hearts or at subcutaneous locations, respectively. At no other location of the body of the SCID mice a cell engraftment was detected.

To better understand the fate of the delivered ASCs, we investigated subcutaneous tissue harvested at the injection site at four weeks after subcutaneous application of human ASCs. Immunofluorescent detection of von Willebrand factor (red signal in Fig. 23h) and Lamin A/C (green signal in Fig. 23h) demonstrated that the human ASCs delivered into a subcutaneous location of a SCID mouse participated in the formation of new blood vessels.

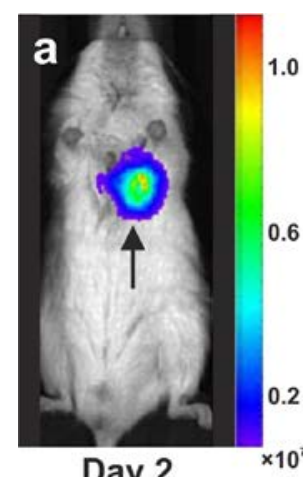

Day 2

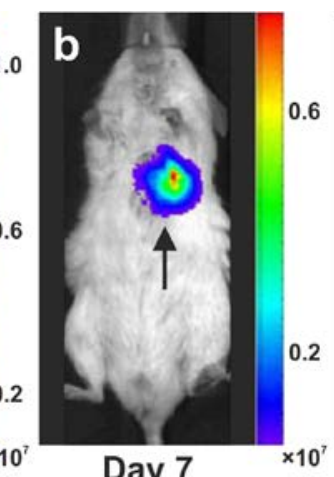

Day 7

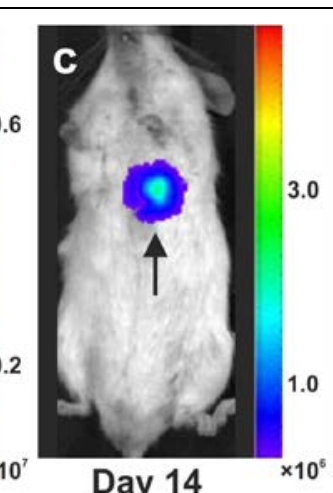

Day 14

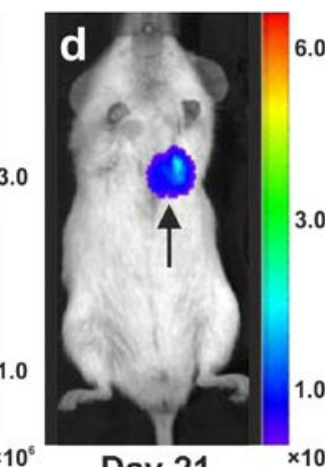

Day 21
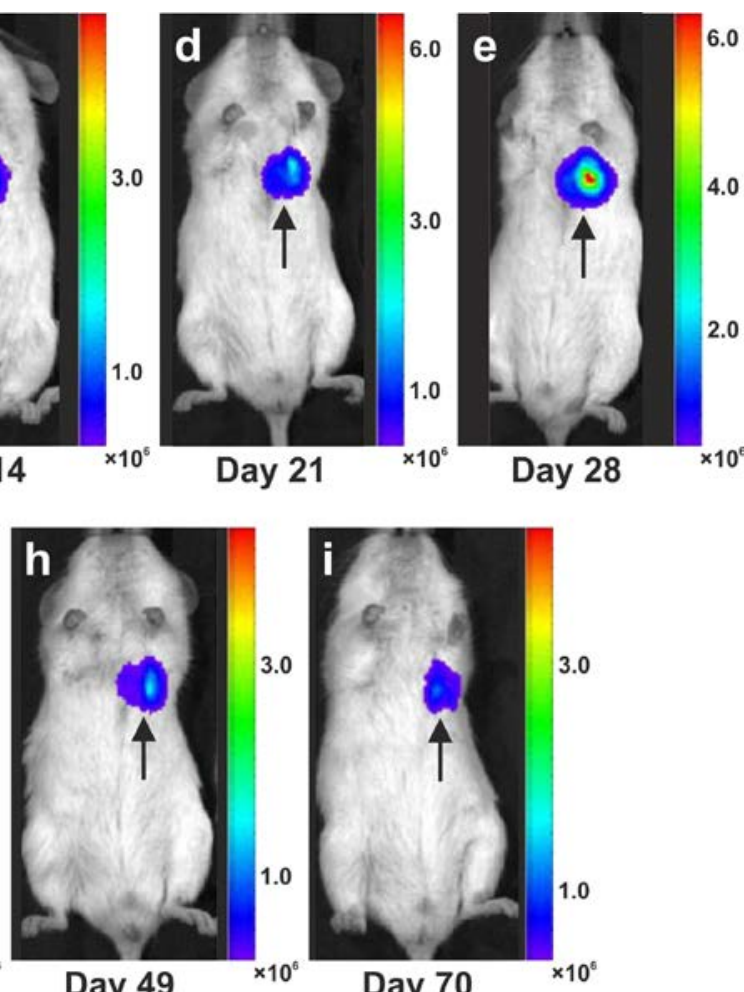

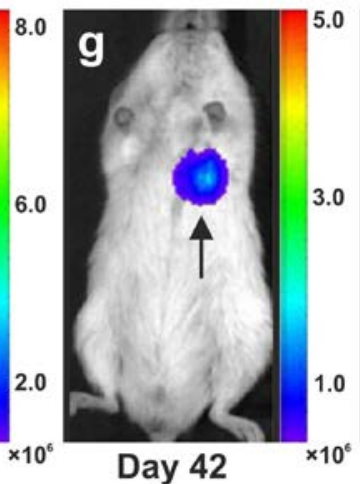

Day 42

Day 49

Day 70

FIGURE 22 | In vivo bioluminescence imaging over time of $5 \times 105$ human adipose-derived stem cells (ASCs) that were intramyocardially delivered into SCID mice after experimental induction of myocardial infarction by permanent ligation of the left anterior descending coronary artery. The ASCs were transfected with a lentiviral vector expressing green fluorescent protein and luciferase. Strong bioluminescence signals were found over the heart region at all investigated time points (arrows), indicating the long-term survival of delivered ASCs in injured hearts (modified from Bai et al., 2011).

\subsection{Specific therapeutic benefits of adipose- derived regenerative cells}

One of the most striking features of ADRCs in cell-based therapy is their pluripotent differentiation potential without any prior manipulation, genetic alteration or the need for culturing. Also, the use of ADRCs in cell-based therapies has a number of additional benefits. Specifically, ADRCs can be (i) obtained from a small amount of adipose tissue when using the appropriate technology for isolating the cells; and (ii) harvested from and re-applied to the same patient at the point of care without the need for expensive equipment, complicated processing or 
repeat interventions.

It is crucial to bear in mind that in contrast to ASCs, fresh, uncultured ADRCs in principle cannot be labeled. Accordingly, it is not possible to experimentally determine whether the following benefits of ASCs also apply to ADRCs (although it is reasonable to hypothesize that this is indeed the case). Specifically, ASCs can (i) stay locally, survive and engraft in the new host tissue into which the cells were applied; (ii) differentiate under guidance of the new microenvironment into cells of all three germ layers (c.f. Figs 13-15); (iii) integrate into and communicate within the new host tissue by forming direct cell-cell contacts (c.f. Fig. 17); (iv) exchange genetic and epigenetic information through release of exosomes (Fig. 18); (v) participate in building new vascular structures in the host tissue (c.f. Fig. 23h and, e.g., Haenel et al., 2018); (vi) positively influence the new host tissue by release of cytokines (among them vascular endothelial growth factor and insulin-like growth factor 1) (Sadat et al., 2007); (vii) protect cells at risk in the new host tissue from undergoing apoptosis (Sadat et al., 2007); and (viii) induce immunemodulatory and anti-inflammatory properties (c.f., e.g., González et al., 2009; Leto Barone et al., 2013), whereby the inhibiting effect on apoptosis may play an important role (Fig. 20).

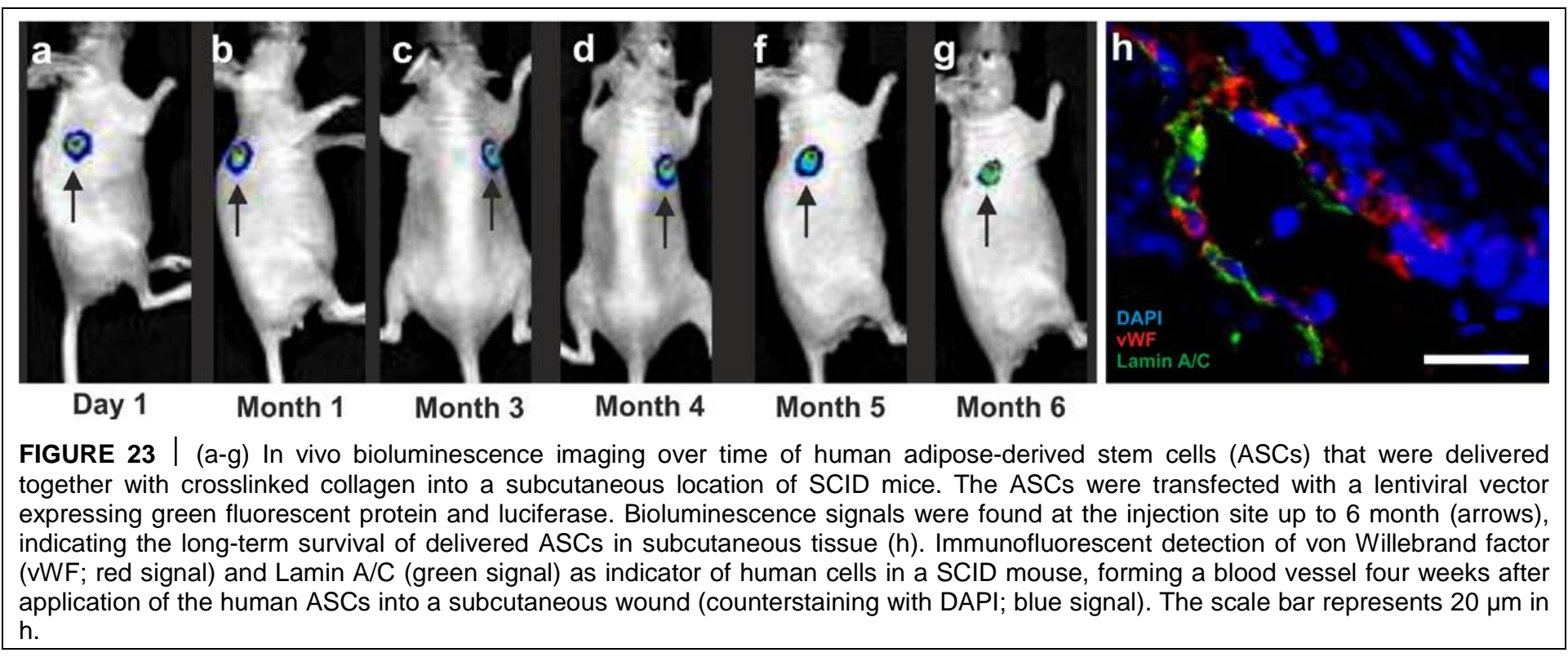

\section{Examples of application of unmodified, autologous adipose-derived regenerative cells (UA-ADRCs) in the praxis of regenerative cell therapy}

\subsection{Should UA-ADRCs be applied locally or systemically?}

It has been shown from experimental data that local injection of stem cells is safe (Altman et al., 2011) as typically a local inflammatory trigger retains stem cells at the site of injection. Meta analyses of clinical results as well have confirmed the safety of stem cell therapy in various indications (Lalu et al. 2012, Ra et al., 2011, Hoffmann and Dow, 2016).

When stem cells are injected into the circulation, they are 'searching' for a place where they could be of benefit. As a tumor is considered a 'wound that does not heal' (Flier, Underhill and Dvorak, 1986; Dvorak, 2015), it releases cytokines and other factors that aim to attract circulating stem cells to the tumor site (c.f., e.g., Gehmert et al., 2010; Ilmer et al., 2014; Kruger et al., 2014), where stem cells may assist the tumor to build its stroma and thereby help the tumor to grow faster (Altman et al., 2009). Hence, UA-ADRCs preferably should be applied locally to the side of need. In case of systemic application the potential of UA-ADRCs to support an already existing tumor in its growth (in contrast to the absent ability of UA-ADRCs to induce a de novo tumor) should be considered, pointing to the need for evaluation of the oncogenic status of the patient prior to a systemic application.

\subsection{Cartilage defects}

The advantages of treating cartilage defects with UAADRCs are exemplified by the following example of a male, 51-year-old patient who presented with recurring and increasing pain in both knee joints during walking and 
other activities (all treatments and procedures described in this section were performed in the framework of a clinical study that was approved by the Freiburg Ethics Commission International (feki; Freiburg, Germany) (feki code 013/1371)). The patient's history included a tibial chondrocyte transplant that had been performed three years previously. Figure 24a shows an arthroscopic view of third-degree damage to the right tibial plateau where the transplanted chondrocytes were gone and only the artificial matrix with small holes implanted on the tibial plateau was still present (white asterisk in Fig. 24a). Furthermore, considerable osteoarthritic damage of the femoral cartilage was observed (black asterisk in Fig. 24a). Figure 24b shows the situation after arthroscopic removal of the failed chondrocyte transplant (white asterisk in Fig. 24b) as well as 'mushy' and damaged cartilage structure on the femoral condyles before it was removed (black asterisk in Fig. 24b). Then, the right knee was treated with a single application of UA-ADRCs obtained from $50 \mathrm{~g}$ of abdominal adipose tissue. A control arthroscopy one year later showed complete healing of the tibial defect (white asterisk in Fig. 24c) and of the femoral parts, with formation of new whitish cartilage that showed a sharp demarcation border to the original, more yellowish cartilage (arrows in Fig. 24c). The left knee of the same patient was treated with a standard procedure without application of UA-ADRCs, i.e., arthroscopic removal of damaged cartilage and drilling of small holes into the bone. A control arthroscopy one year later showed a somewhat uneven, overshooting fibroblastic scar formation (asterisk in Fig. 24d) without a sharp demarcation border to the original cartilage (arrows in Fig. 24d). This indicated that there was some sort of healing, but not a regrowth of organized cartilage, as we hypothesize for the right knee after application of UAADRCs.

Figure 25 shows arthroscopic views of cartilage defects of the knees of two other patients that were also successfully treated with UA-ADRCs. Of note, the finding of a sharp demarcation border between the newly formed cartilage and the original cartilage (arrows in Fig. 24c) was found as well in these patients one year after treatment with UA-ADRCs (arrows in Fig. 25b,d). Again, we hypothesized that this arthroscopic finding indicated regrowth of organized cartilage.

To test the hypothesis that the sharp demarcation borders between the newly and the original cartilage (arrows in Fig. 24c and Fig. 25b,d) indicated regrowth of organized cartilage after application of UA-ADRCs, we obtained written, informed consent by the patient represented in Fig. 24 that small tissue samples could be taken from the regenerated tissue during the follow-up arthroscopy. Histologic analysis of the tissue samples showed two key differences between the samples: (i) After application of UA-ADRCs the newly formed cartilage showed (like in a textbook of histology; c.f., e.g., Jung, 2014) a zonal organization with differently shaped chondrocytes in a superficial, middle and deep layer (Fig. 26). In contrast, without application of UA-ADRCs a more amorphous fibrocartilage with scattered cells (arrows in Fig. 26b) was achieved that had no such layered organization (Fig. 26b).

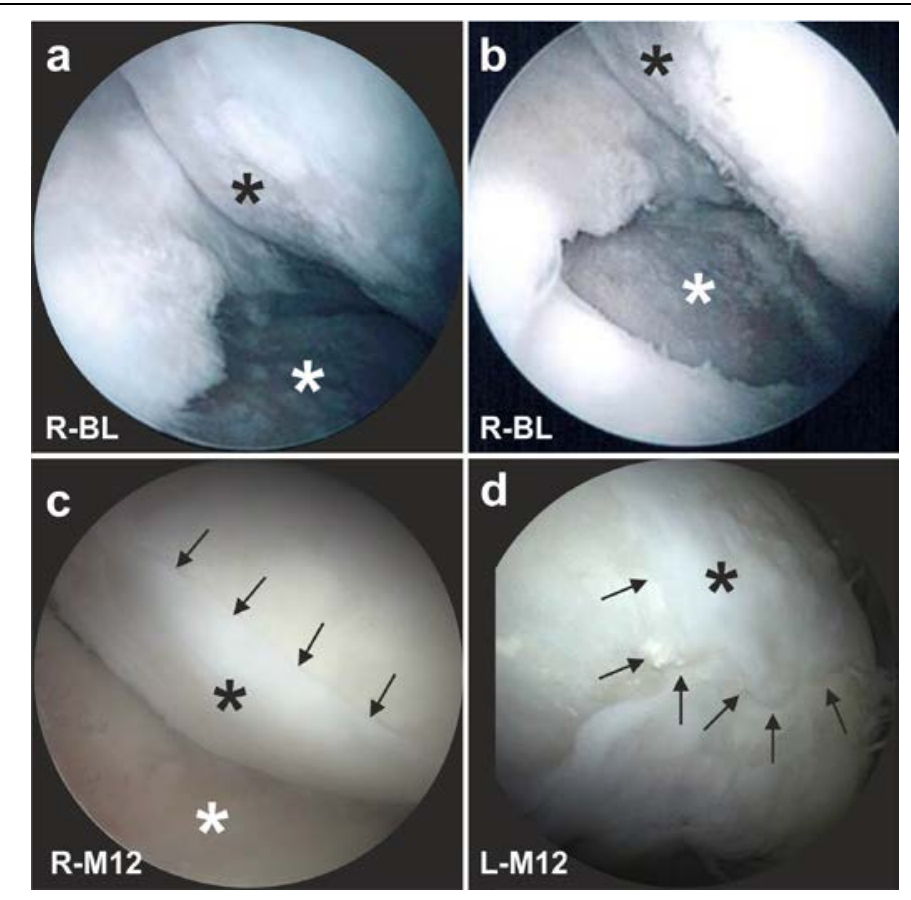

FIGURE 24 | Example of successful application of unmodified autologous adipose-derived regenerative cells (UA-ADRCs) for treating cartilage defects. The panels show arthroscopic views of the right (a-c) and the left (d) knee of a male, 51-year-old patient who presented with recurring and increasing pain in both knee joints during walking and other activities. (a) Third-degree damage to the right tibial plateau (white asterisk) after a tibial chondrocyte transplantation that had been performed three years previously, as well as considerable osteoarthritic damage of the femoral cartilage (black asterisk). (b) Situation of the right knee after arthroscopic removal of the failed chondrocyte transplant (white asterisk) as well as 'mushy' and damaged cartilage structure on the femoral condyles before it was removed (black asterisk). (c) Situation of the right knee one year after arthroscopic removal of damaged cartilage and a single application of UA-ADRCs isolated from $100 \mathrm{ml}$ lipoaspirate, showing complete healing of the tibial defect (white asterisk) and of the femoral parts, with formation of new whitish cartilage that shows a sharp demarcation border to the existing old and more yellowish cartilage (arrows). (d) Situation of the left knee one year after performing a standard procedure without application of UA-ADRCs (i.e., arthroscopic removal of damaged cartilage and drilling of small holes into the bone), showing a somewhat uneven, overshooting fibroblastic scar formation (black asterisk) without a sharp demarcation border to the original cartilage (arrows). Abbreviations: R, right; L, left; BL, baseline; M12, twelve months after baseline. 


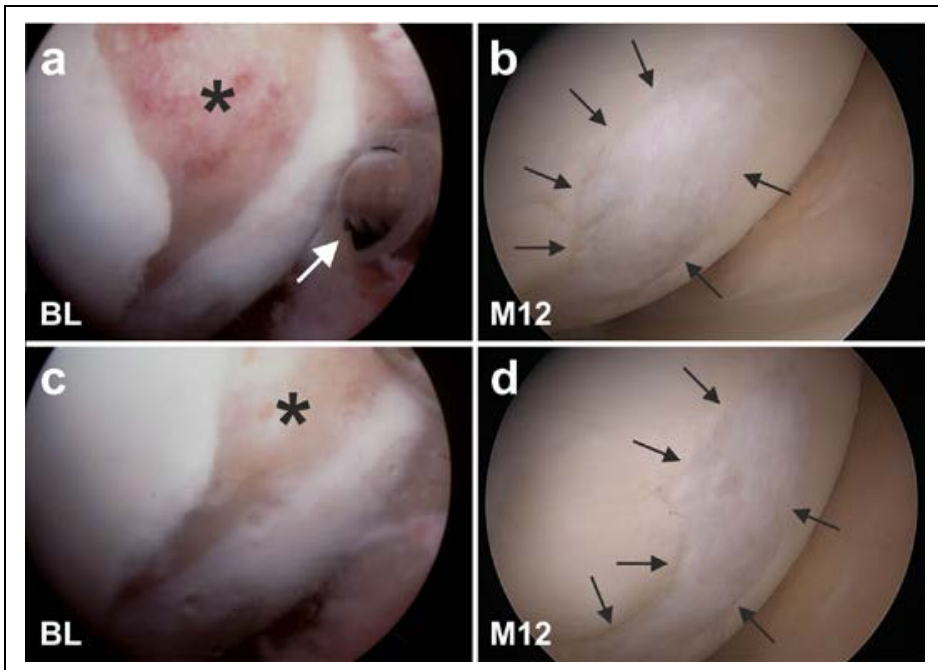

FIGURE 25 Other examples of successful application of unmodified autologous adipose-derived regenerative cells (UAADRCs) for treating cartilage defects. The panels show arthroscopic views of the knees of two patients (Patient 1 [male, 45 years old]: a,b; Patient 2 [male, 55 years old]: $c, d)$ before (a, c) and one year after (b,d) arthroscopic removal of damaged cartilage (asterisks in a,c) and application of UA-ADRCs isolated from $50 \mathrm{ml}$ lipoaspirate. The arrows in $(b, d)$ indicate the sharp demarcation border between the newly formed and the original cartilage. The white arrow in (a) points to the arthroscopic instrument that was used to remove damaged cartilage.

(ii) Furthermore, after application of UA-ADRCs the contact zone between the newly formed cartilage and bone showed (also like in a textbook of histology) typical chondrocytes with a small nucleus and a hollow space around (arrows in Fig. 26c). In contrast, without application of UA-ADRCs the contact zone between the newly formed cartilage and bone showed an infiltration with inflammatory cells, fibroblasts (arrows in Fig. 26d) and small blood vessels (arrowheads in Fig. 26d).

Analysis of the tissue sample taken during arthroscopic inspection of the right knee of the patient represented in Fig. 24 at one year after arthroscopic removal of damaged cartilage and a single application of UA-ADRCs from 50 $\mathrm{g}$ of his adipose tissue with polarized light microscopy demonstrated that the collagen fiber bundles in the deep and middle layers of the newly formed cartilage show a more vertical orientation (i.e., perpendicular to the border between bone and cartilage), whereas the collagen fiber bundles in the superficial layer showed a more horizontal orientation (i.e., parallel to the surface) (Fig. 27). This finding is in line with the description of the physiologic orientation of collagen fiber bundles in articular cartilage in the literature when analyzed with polarized light microscopy (e.g., Rieppo et al., 2008).

To our knowledge, the results presented in this section go beyond the state-of-the-art in the field of regenerating damaged cartilage with ADRCs and ASCs. In a recent review (Damia et al., 2018) a number of clinical studies were listed in which cartilage defects in the human knee were treated with ASCs (Jo et al., 2014; Pers et al., 2016; Freitag et al., 2017). Of note, in all of these studies ASCs were applied, whereas we have been using fresh uncultured ADRCs (for the advantages of ADRCs over ASCs see Sections 4.1. and 4.4.). The maximum followup period in the studies by Jo et al. (2014) and Pers et al. (2016) was only six months after application of ASCs (MRI, arthroscopy and histologic analysis in both studies; $\mathrm{n}=18$ patients in both studies). In the single case report by Freitag et al. (2017) MRI was performed at twelve months after application of ASCs, but no arthroscopy and, thus, no histologic analysis. Furthermore, in none of these studies tissue samples were ever investigated with polarized light microscopy.

\subsection{Chronic, recalcitrant low back pain caused by lumbosacral facet syndrome}

Lumbosacral facet syndrome is a term used to describe a painful condition caused by inflammation and irritation of the zygapophyseal (facet) joints of the spine (Fig. 28a-c). It is most commonly caused by chronic degenerative changes in the lumbosacral spine. Symptoms include low back pain with or without referral to the lower extremities (Alexander and Dulebohn, 2018). To our knowledge, reports on cell-based therapies for chronic low back pain caused by lumbosacral facet syndrome have not yet been published.

Figure 28d-f shows typical wear and tear that occurred in the spine of three former professional ski racers (all treatments and procedures described in this section were performed in the framework of clinical assessment). The green arrows indicate normal intervertebral disc structure between the lumbar vertebrae L3 and L4, demonstrating that there was a certain level of water content, reflected by the white signal in the MRI. In contrast, the yellow arrows show that between vertebrae L4 and L5 in all three athletes there was a reduction in height of the intervertebral disc due to the diminished overall volume of the intervertebral disc. The increased body weight now resting on the facet joints results in an inflammatory reaction of the facet joints. All three athletes were treated with UA-ADRCs. The cells were injected into the right and left facet joints between L4 and L5 as well as between L5 and S1 within a single procedure of harvesting and injection that lasted about two hours. This treatment resulted in a significant and long lasting (now more than three years) pain reduction that enabled these athletes to return to successful competitive sports. 


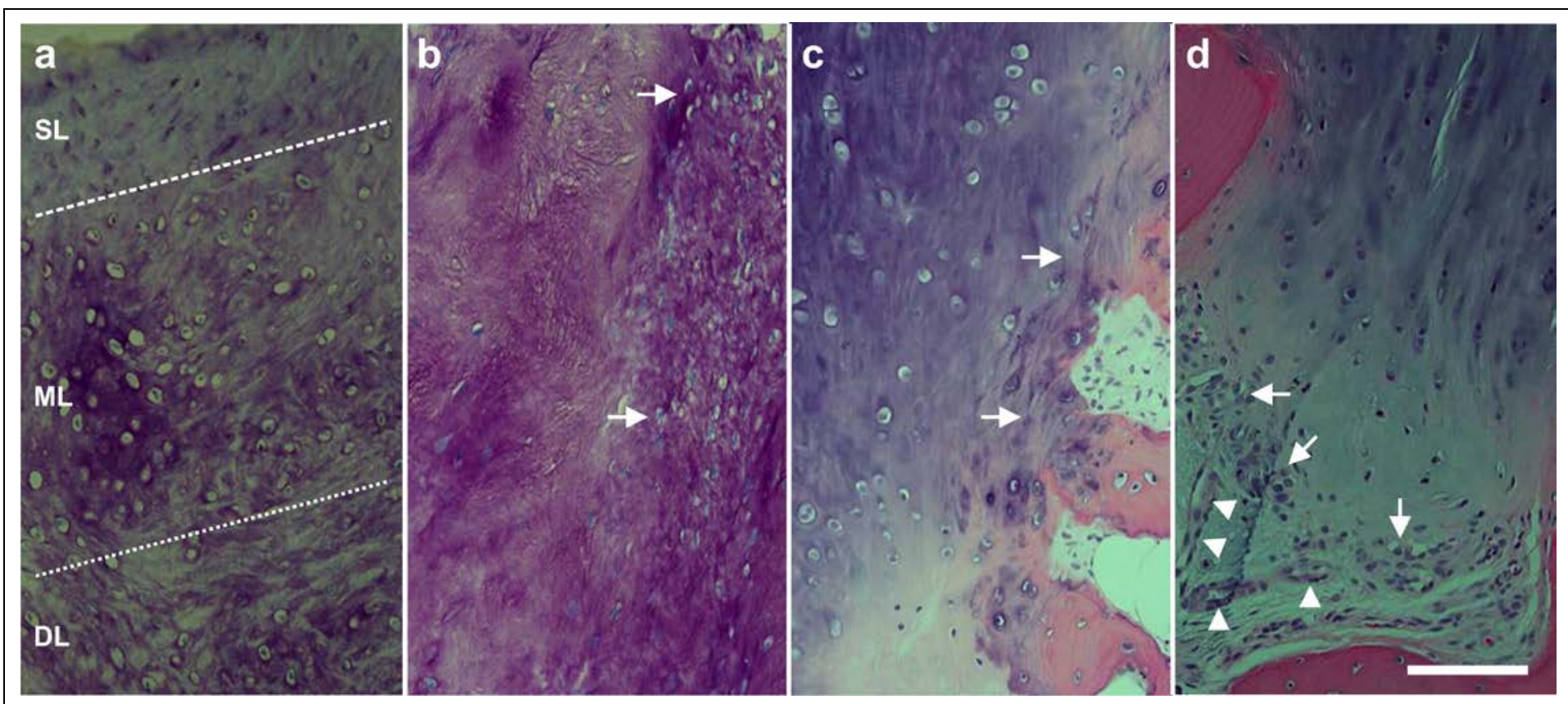

FIGURE 26 |Representative photomicrographs of $5 \mu \mathrm{m}$ thick histologic sections (stained with toluidin blue [a,b] or hematoxylin and eosin stain [c,d]) of the small tissue samples taken during arthroscopic inspection of the knees of the patient represented in Fig. 24 at one year after arthroscopic removal of damaged cartilage and a single application of unmodified autologous adipose-derived regenerative cells (UA-ADRCs) (right knee) (a,c) or after performing a standard procedure without application of UA-ADRCs (i.e., arthroscopic removal of damaged cartilage and drilling of small holes into the bone) (left knee) (b,d), respectively. The dotted lines in (a) indicate a zonal organization of the newly formed cartilage with differently shaped chondrocytes in a superficial (SL), middle (ML) and deep layer (DL). The arrows in (b) point to scattered cells within newly formed amorphous fibrocartilage. The arrows in (c) indicate typical chondrocytes with a small nucleus and a hollow space around in the contact zone between the newly formed cartilage and bone, whereas the arrows in (d) point to an infiltration with inflammatory cells in the contact zone between the newly formed cartilage and bone. The arrowheads in (d) indicate small blood vessels. The scale bar represents $100 \mu \mathrm{m}$.

Figure 29 shows individual pain scores on a VAS scale (with 0 representing no pain and 10 representing maximum, unbearable pain) of $n=39$ patients with chronic, recalcitrant low back pain caused by lumbosacral facet syndrome before (red dots in Fig. 29) and one year after (green dots in Fig. 29) treatment with UA-ADRCs isolated from $100 \mathrm{ml}$ lipoaspirate each (the follow-up interval ranged between twelve months and more than three years) (modified from Rothoerl et al., 2016) (all treatments and procedures described in this section were performed in the framework of a clinical study that was approved by the Freiburg Ethics Commission International (feki; Freiburg, Germany) (feki code 016/1252)). The mean and standard error of the mean of the VAS scores before and after treatment was $7.21 \pm 0.17$ and $1.80 \pm 0.17$; this difference was highly statistically significant (Wilcoxon matchedpairs signed rank test; $p<0.001$ ). As a consequence, the quality of life of these patients was significantly improved.

Figure 30 shows mean and standard deviation of the individual improvement of the VAS score after treatment as a function of the VAS score before treatment of these 39 patients. Linear regression analysis showed a statistically significant relationship between the VAS score before treatment and the individual improvement of the VAS score after treatment, with the best results obtained with the highest VAS scores before treatment (r2 $=-0.22 ; p=0.003)$. This impressively demonstrates the potential of UA-ADRCs for the treatment of chronic, recalcitrant low back pain caused by lumbosacral facet syndrome, and perhaps opens the possibility for obtaining comparable results for other chronic pain conditions of the musculoskeletal system. 


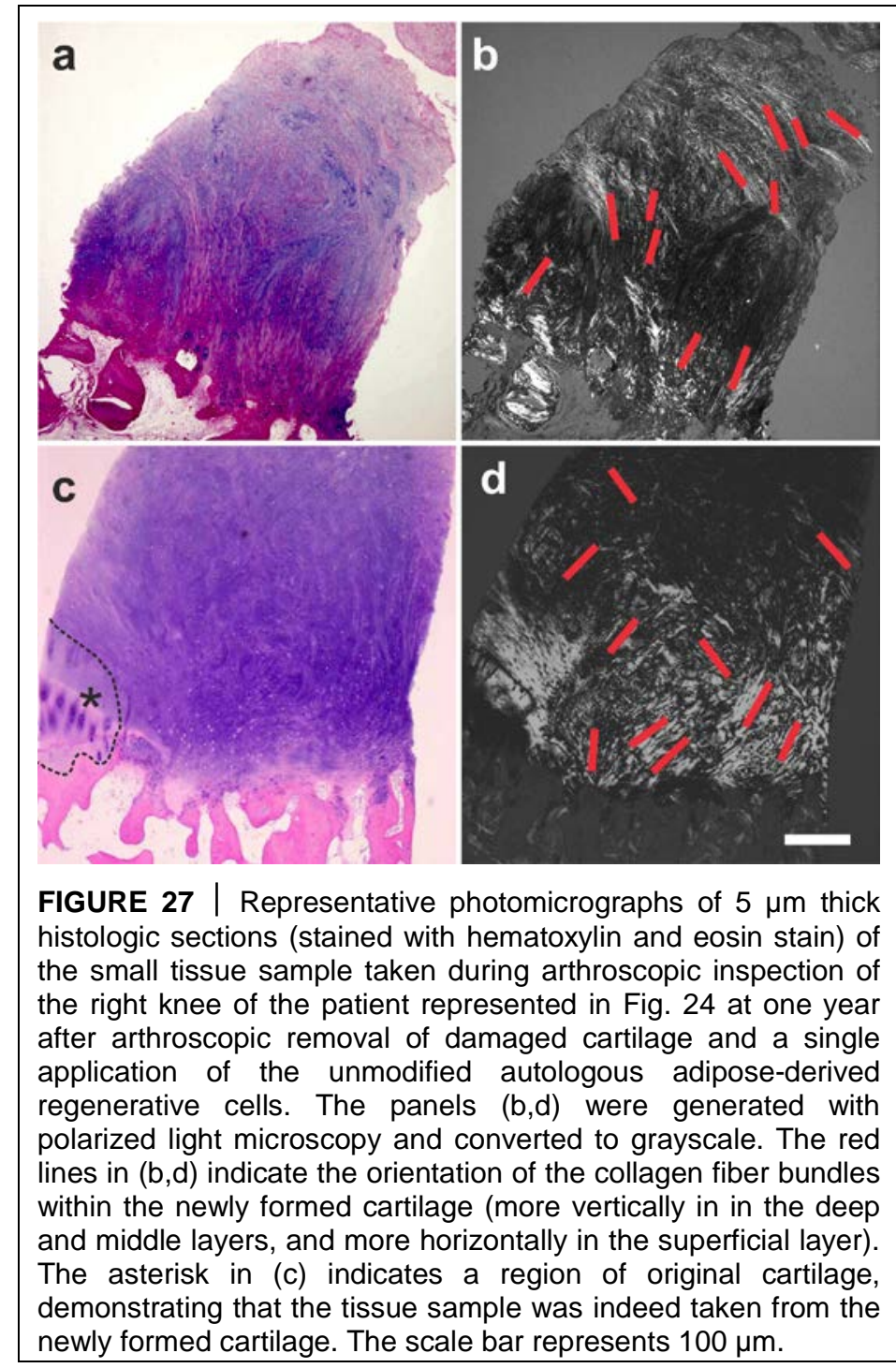

\subsection{Guided bone regeneration}

The promising results achieved in the treatment of cartilage defects and chronic, recalcitrant low back pain caused by lumbosacral facet syndrome (described in detail in Sections 5.1. and 5.2.) gave reason to hypothesize that the application of UA-ADRCs could also advance the treatment of other pathologies of the musculoskeletal system. In this regard it was a key finding that in guided bone regeneration (GBR) (exemplified by a case of a 79year old patient who presented with a partly failing maxillary dentition and who was treated with a bilateral external sinus lift procedure as well as a bilateral lateral alveolar ridge augmentation) the combined application of UA-ADRCs, Fraction 2 of plasma rich in growth factors (PRGF-2) and an osteoinductive scaffold (OIS) (Treatment A) was superior to the combination of PRGF-2 and the same OIS alone (Treatment B) (Solakoglu et al., 2019) (these treatments and procedures were performed in the framework of a clinical study that was approved by the Ethics Committee of the Federal Dental Association Hamburg (Hamburg, Germany) (no. PV5211)). Specifically, Treatment A resulted in faster build up of higher relative amounts (area/area) of newly formed bone, connective tissue and arteries as well as in lower relative amounts of adipocytes and veins at 34 weeks after GBR (Fig. 31a,b) comparted to standard treatment without stem cells.

Avascular necrosis of the femoral head is one of the many indications where bone regeneration is essential for rehabilitation (e.g., Larson et al., 2018). Cell-based therapy for this pathology has been addressed in a number of clinical studies (for a recent systematic review and meta-analysis see, e.g., Andriolo et al., 2018). One of these studies was a case report of a 43-year-old male patient who was successfully treated with ADRCs mixed with platelet-rich plasma and hyaluronic acid (Pak et al., 2014). We went one step further and treated a 41-year-old male patient suffering from avascular necrosis of the femoral head only with ADRCs (all treatments and procedures were performed in the framework of clinical assessment). Figure 31c shows an MRI scan of the left hip of this patient who was confined to a wheelchair because of unbearable pain during walking, with a significant necrotic space in the head of the patient's left femur. Six months after two applications of UA-ADRCs (that were locally injected through a channel which came through the lateral side of the greater trochanter) a control MRI scan showed a markedly improved situation (Fig. 31d), and the patient could leave the wheelchair and walks now without pain. 

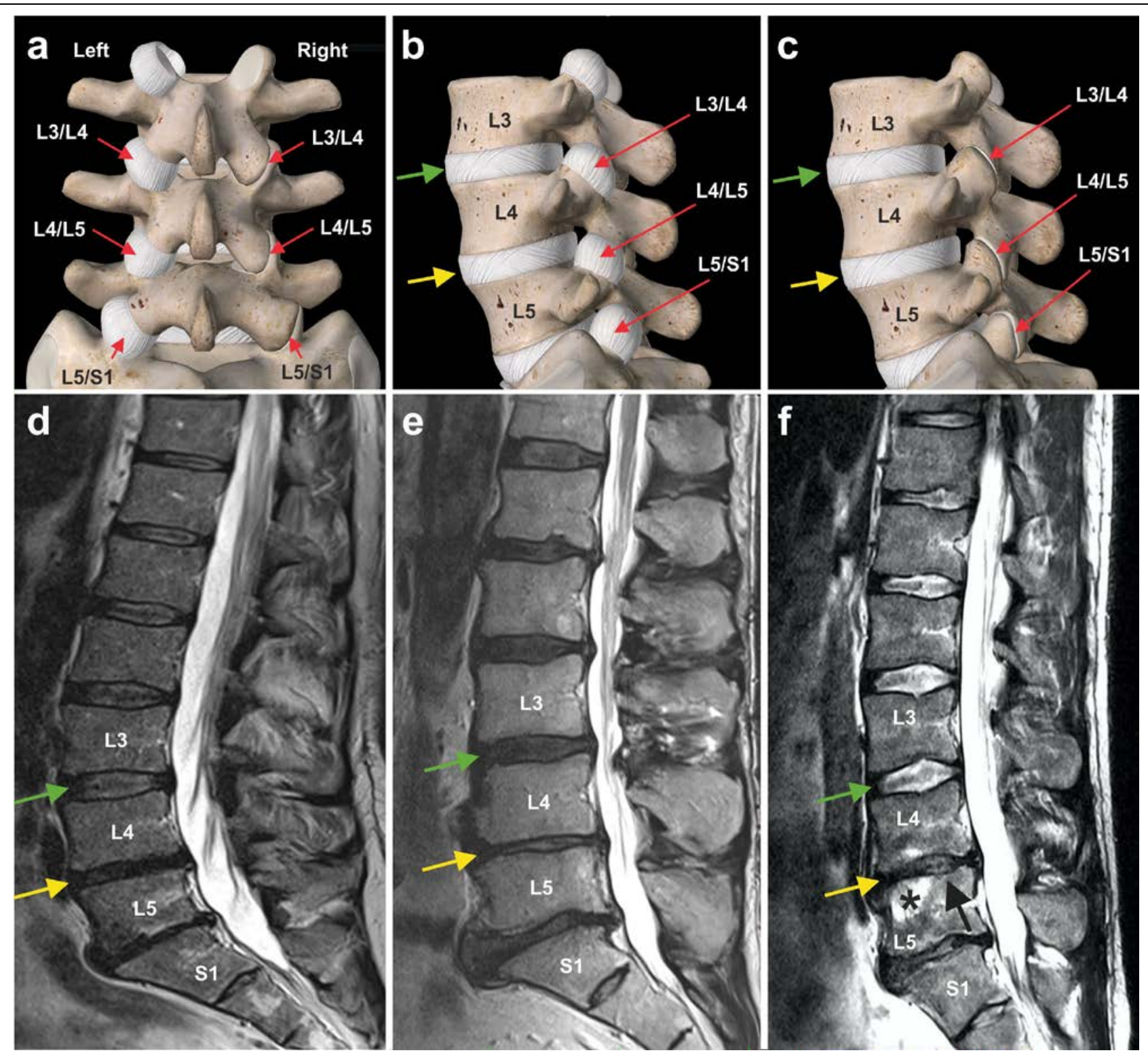

FIGURE 28 | (a-c) Schematic of the lumbar vertebrae L3-L5 and the upper edge of the os sacrum of a human spine from dorsal (a) and lateral (b,c). The red arrows indicate the zygapophyseal (facet) joints between L3 and L4 (L3/L4), between L4 and L5 (L4/L5) and between L5 and the os sacrum (L5/S1) with joint capsule (on the left side in a and in b) as well as without joint capsule (on the right side in $a$ and in c). The green arrows in (b,c) indicate the intervertebral disc between $L 3$ and $L 4$, and the yellow arrows the intervertebral disc between L4 and L5. (d-f) MRI scans of the lumbar spine (from lateral) of three former professional, internationally highly successful ski racers (we are not allowed to provide more information about these patients in order to protect privacy). The green arrows indicate normal intervertebral disc structure between $L 3$ and $L 4$, whereas the yellow arrows show that in all three athletes there was a reduction in the height of the intervertebral disc (and, thus, the intervertebral space) between L4 and L5. The asterisk in ( $f$ ) points to a bone marrow edema in the vertebral body of L5, and the black arrow in (f) to an upper plate collapse of L5. All three athletes were treated with unmodified autologous adipose-derived regenerative cells. The cells were injected into the right and left facet joints between L4 and L5 as well as between L5 and S1 within a single procedure of harvesting and injection that lasted about two hours. This treatment resulted in a significant and long lasting (now more than three years) pain reduction that enabled these athletes to return to successful competitive sports. 


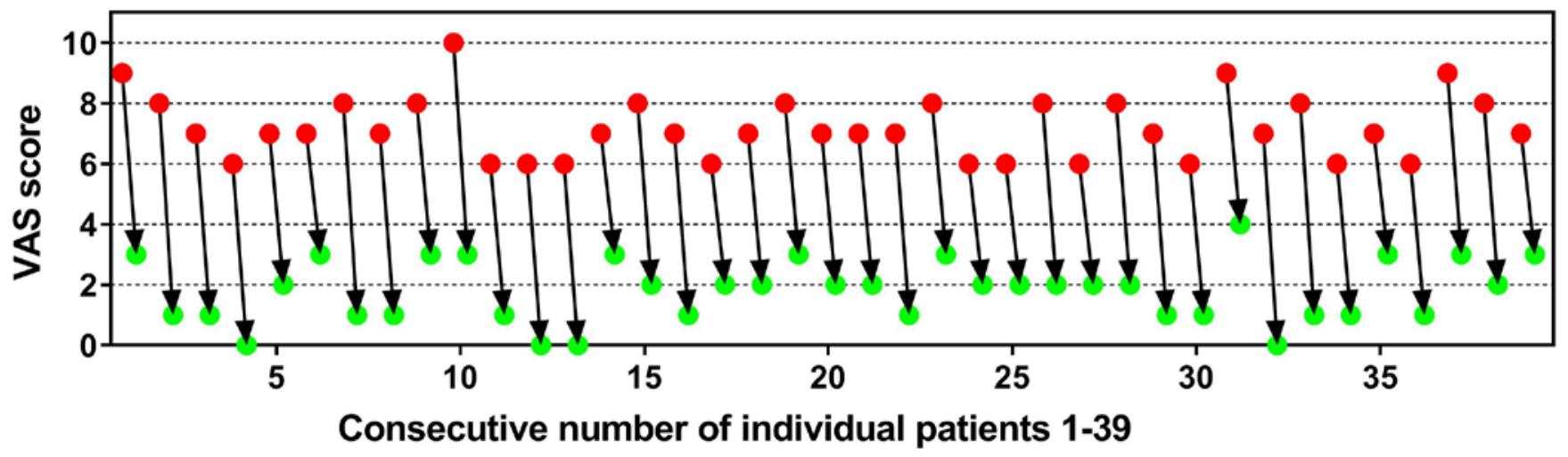

FIGURE 29 Individual VAS scores of $n=39$ patients with chronic, recalcitrant low back pain caused by lumbosacral facet syndrome before (red dots) and after (green dots) treatment with UA-ADRCs isolated from $100 \mathrm{ml}$ lipoaspirate each (the follow-up data ranged between six months and three years) (modified from Rothoerl et al., 2016). The patients were listed consecutively according to the date of treatment.

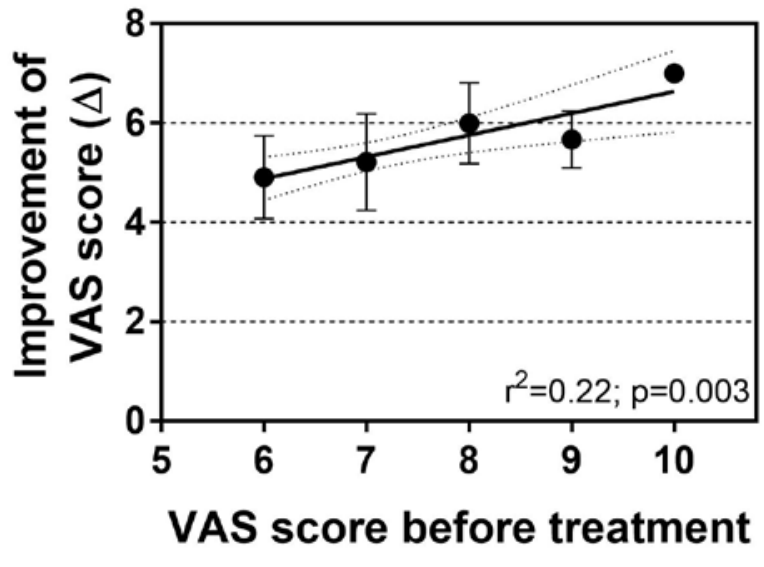

FIGURE $30 \mid(a, b)$ Representative photomicrographs of $3 \mu \mathrm{m}$ thick paraffin sections stained with hematoxylin and eosin stain of biopsies that were collected at 34 weeks after performing guided bone regeneration (in the framework of a bilateral external sinus lift procedure as well as a bilateral lateral alveolar ridge augmentation in a 79-year old patient who presented with a partly failing maxillary dentition) using a combination of approximately 50×106 unmodified autologous adipose-derived regenerative cells (UA-ADRCs), Fraction 2 of plasma rich in growth factors (PRGF-2) and an osteoinductive scaffold (OIS) (right side) (a) or a combination of PRGF-2 and the same OIS alone (left side) (b). Abbreviations: A, adipocytes; B, newly formed bone; S, scaffold; V, veins. The scale bar represents 100 $\mu \mathrm{m}$. (c,d) MRI scans of the left hip of a 41-year-old male patient suffering from avascular necrosis of the femoral head (arrows in $\mathrm{c}, \mathrm{d})$ at baseline (c) and at six months after two applications of UA-ADRCs.

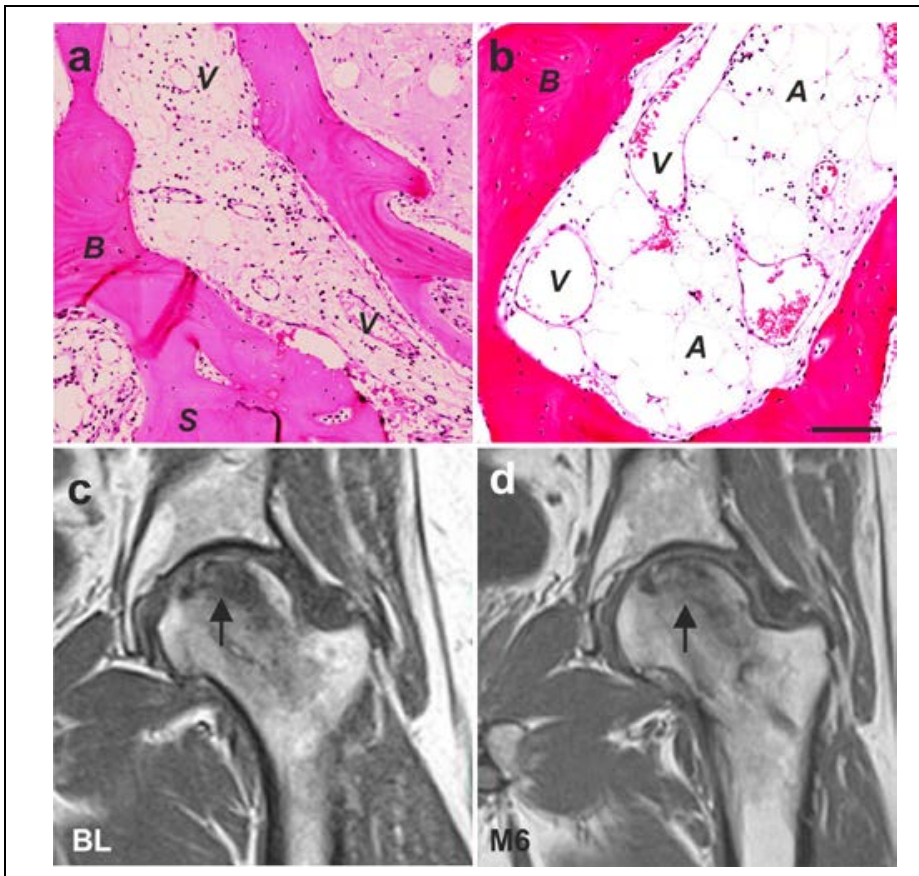

FIGURE $31 \mid(a, b)$ Representative photomicrographs of $3 \mu \mathrm{m}$ thick paraffin sections stained with hematoxylin and eosin stain of biopsies that were collected at 34 weeks after performing guided bone regeneration (in the framework of a bilateral external sinus lift procedure as well as a bilateral lateral alveolar ridge augmentation in a 79-year old patient who presented with a partly failing maxillary dentition) using a combination of approximately $50 \times 106$ unmodified autologous adipose-derived regenerative cells (UA-ADRCs), Fraction 2 of plasma rich in growth factors (PRGF-2) and an osteoinductive scaffold (OIS) (right side) (a) or a combination of PRGF-2 and the same OIS alone (left side) (b). Abbreviations: A, adipocytes; B, newly formed bone; S, scaffold; V, veins. The scale bar represents 100 $\mu \mathrm{m}$. (c,d) MRI scans of the left hip of a 41-year-old male patient suffering from avascular necrosis of the femoral head (arrows in c,d) at baseline (c) and at six months after two applications of UA-ADRCs. 
Adipose-derived regenerative cells

\subsection{Examples of other treatments with UA- ADRCs}

Several studies on animal models and clinical pilot studies have shown that human ADRCs and ASCs are able to enhance and accelerate wound healing, especially in chronic wounds (e.g., Altman et al., 2009; Sorice et al., 2016; Konstantinow et al., 2017). An example of successful application of UA-ADRCs for treating chronic wounds in humans is shown in Figure 32, which represent cases of prolonged wounds that did not heal for several years (these treatments and procedures were performed in the framework of a clinical study that was approved by the Ethics Committee of the Medical Faculty of the Technical University Munich (Munich, Germany) (no. 5639/12)). The underlying principle in those wounds is that the regenerative power of the local stem cells is exhausted due to the repeated futile attempts at healing. Debridement of the wounds showed that debrided tissue contained only very few living cells. The transfer of UA-ADRCs activated the wounds after a few days and induced shrinkage and significant reduction of the inflammatory redness. Typically, after two to three months all wounds based on venous insufficiency were closed. Of note, the images shown in Figure 32 impressively demonstrate that UA-ADRCs do not only work in younger people. In one 85-year-old patient who suffered from open leg wounds of more than $100 \mathrm{~cm} 2$ for several years, healing was obtained after a single application of UA-ADRCs (Fig. 32c).

Primarily not considered a mainstream indication for stem cell therapy, there is anecdotal evidence indicating that UA-ADRCs have a great effect on remodeling of scar tissue. As demonstrated in Figure 33, the degradation of the extracellular matrix, which leads to scarring, can be reversed (all treatments and procedures described in this section were performed in the framework of clinical assessment). We still do not fully understand the exact mechanisms behind this effect (Altman et al., 2009; 2010) However, the expression of matrix metalloproteinases 2 and 9, which enable MSCs to migrate through tissue (e.g., Pourjafar et al., 2017), might be responsible for the realignment of the extracellular matrix. We hypothesize that scar tissue becomes primarily decomposed and degraded by MSCs when they migrate through tissue, and afterwards, the extracellular matrix is recomposed and restructured by a part of the posterior cell body of the MSCs (c.f., e.g., Te Boekhorst, Preziosi and Friedl, 2016).

Figure 34 shows the effects of UA-ADRCs on hair growth (all treatments and procedures described in this section were performed in the framework of clinical assessment). The mechanism is assumed to be similar to the regeneration of an organ or other tissues. Specifically, we hypothesize that the delivered stem cells most likely 'are guided' by the remaining hair roots to their 'local task' of trans-differentiation into hair.

\section{Outlook}

Regenerative medicine and cell therapy are not yet part of mainstream clinical practice. Therapies based on UAADRCs discussed in this article appear to be highly promising candidates for repair and regeneration of many tissues and ultimately for wide adoption to the practice of medicine. One of the most striking features of UAADRCs is their pluripotent differentiation potential without any prior modification or need for culturing. Furthermore, UA-ADRCs can be obtained from a small amount of adipose tissue when using the appropriate, enzyme-supported technology for isolating true pluripotent stem cells. The fact that tissue can be harvested from and cells can be re-applied to the same patient at the point of care in one clinical session without the need for expensive equipment, complicated processing or repeat interventions indicates easy integration into the clinical workflow.

As with any medical innovation, the scientific and medical community interested in these novel therapies needs to develop sound clinical evidence to further show safety and efficacy of cell-based therapies. Our understanding of the mechanism of actions and potential benefit of stem cell therapy has increased enormously over the past decade and we hope that there is now enough data to convince others to embark on scientifically-designed clinical studies that will provide the necessary objective evidence. Especially musculoskeletal indications with their large incidence and prevalence rates and often substantive total cost of care associated with current clinical practice should prove to be attractive candidates for such efforts.

An important factor for successful implementation of autologous cell therapies will be the proactive support of regulatory authorities to design frameworks that, while addressing valid concerns around the safety of unproven therapies that can be found in some places currently, show a clear path to market approval and reimbursement. Some progress in that direction can be observed in a number of jurisdictions. For example, the US FDA has provided clear guidance for Regenerative Medicine Advanced Therapies in 2017. Other countries such as Japan and Australia also seem to have created an advanced regulatory framework that will allow patients to gain fast access to Regenerative Medicine. Unfortunately, the situation in the European Union (EU) is not yet that clear. A complex set of guidance and regulations that result in somewhat convoluted responsibilities between the EU, Member States and local authorities will need to eventually be streamlined to help to make these promising therapies 
available for all patients in the EU too.

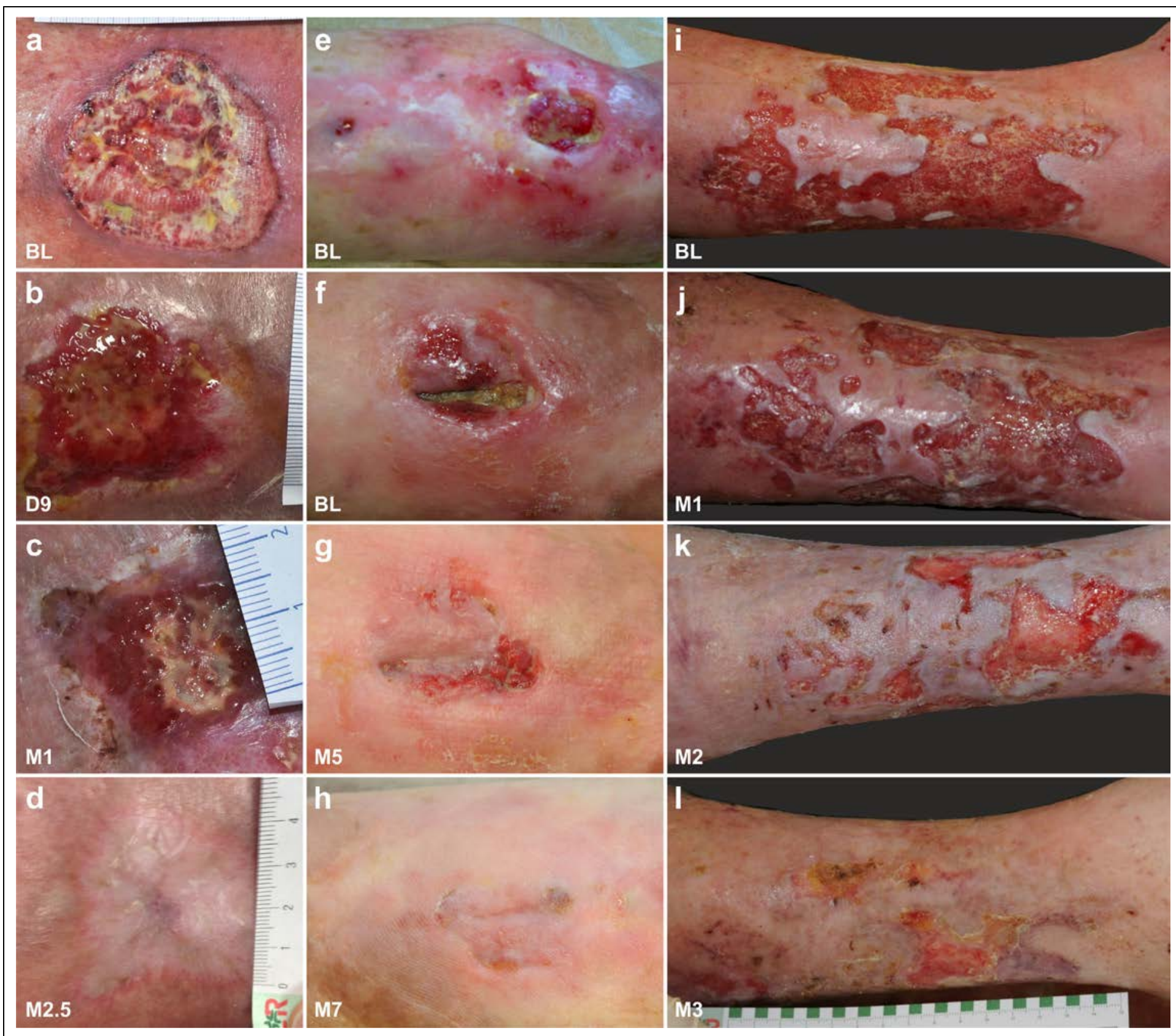

FIGURE 32 | Examples of successful application of unmodified autologous adipose-derived regenerative cells (UA-ADRCs) for treating chronic wounds that did not heal for years. (a-d) Female, 76 year old patient; chronic wound over the medial malleolus; single application of UA-ADRCs isolated from $30 \mathrm{ml}$ lipoaspirate. (e-h) Male, 82 years old patient; chronic wound on the lower leg caused by a phosphorus bomb during World War II; single application of UA-ADRCs isolated from $30 \mathrm{ml}$ lipoaspirate. (i-I) Female, 84 years old patient, chronic wound on the lower leg; single application of UA-ADRCs isolated from $30 \mathrm{ml}$ lipoaspirate. Abbreviations: BL, baseline; D9, nine days after application of UA-ADRCs; M1/M2/M2.5/M3/M5/M7, one/two/two and a half/ three/five/seven months after application of UA-ADRCs.

It is our hope that this article will help to clarify and facilitate the understanding, development and adoption of Regenerative Medicine in general and specifically of therapies based on UA-ADRCs. Not all medical challenges that we face in clinical practice today will be candidates for Regenerative Medicine. But as we are facing more and more age-related diseases, we are convinced that cell based therapies will play a fundamental role in a continously increasing number of indications. This has the potential to trigger the 
development of an entire new generation of medicine for the benefit of patients and of healthcare systems.

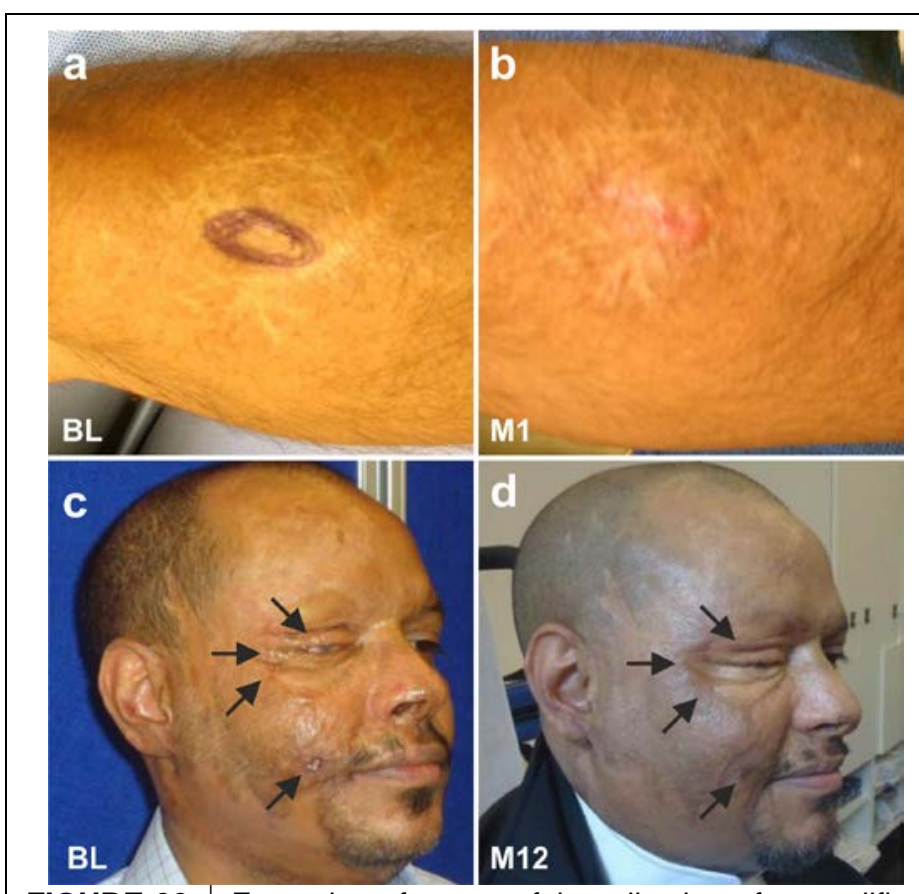

FIGURE 33 Examples of successful application of unmodified autologous adipose-derived regenerative cells (UA-ADRCs) for reducing scar tissue. $(a, b)$ Male, 48-year-old patient; scar tissue formation on the upper arm after an injury caused by a car accident; single application of UA-ADRCs isolated from $100 \mathrm{ml}$ lipoaspirate. (c,d) Male, 50-years-old patient; scar tissue formation (arrows) in the face after an acid attack; three treatments with UA-ADRCs isolated from $100 \mathrm{ml}$ lipoaspirate on days 1, 90 and 180. Abbreviations: BL, baseline; M1/M12, one/twelve months after application of UA-ADRCs.

\section{Ethics}

The different studies during which cells were collected for performing the experiments shown in Figs 2-6, 9-20 and 22-23 were approved by the Institutional Review Boards (IRB) for Baylor College of Medicine and Affiliated Hospitals (Houston, TX, USA) (Protocol \# H-18357) and University of Texas M. D. Anderson Cancer Center (Houston, TX, USA) (Protocol \# 03-08-03031 and 03-0803031).

Killing mice by cervical dislocation for isolating cells from subcutaneous fat tissue (Muehlberg et al., 2009), killing neonatal rats by decapitation for isolating cardiomyocytes (Sadat et al., 2007) and killing adult rats by decapitation for isolating cells (Alt and Bai, unpublished data) did not require IRB approval but was performed following the guidelines of Veterinary Medicine \& Surgery at the University of Texas M. D. Anderson Cancer Center and the U.S. National Institutes of Health.

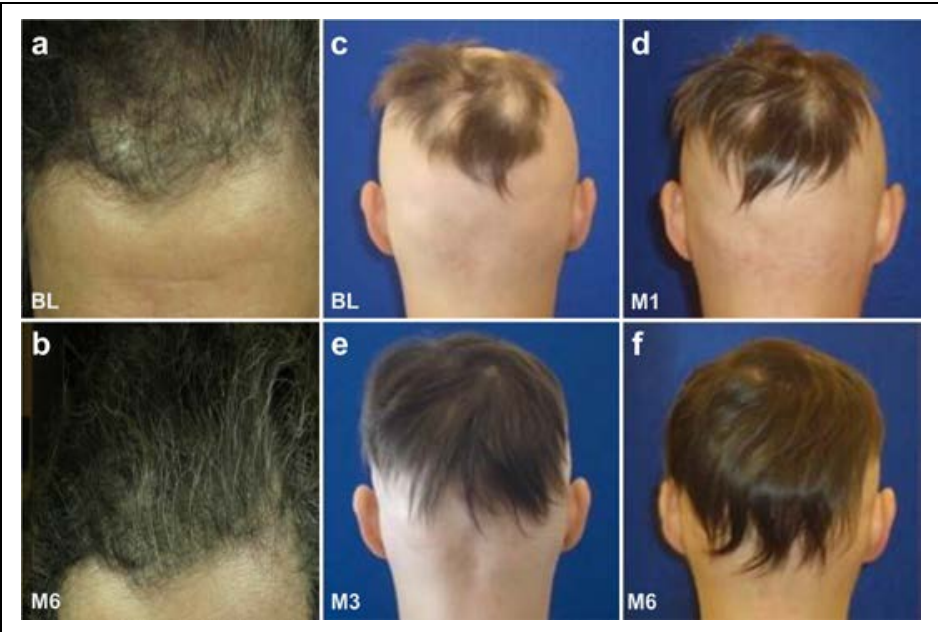

FIGURE 34 | Examples of successful application of unmodified autologous adipose-derived regenerative cells (UA-ADRCs) for treating hair loss. $(a, b)$ 46-year-old female patient; sparse hair; single application of UA-ADRCs isolated from $100 \mathrm{ml}$ lipoaspirate. (c-f) 23-years-old female patient suffering from atopic dermatitis and alopecia totalis for three years without spontaneous improvement; three treatments with UA-ADRCs isolated from $100 \mathrm{ml}$ lipoaspirate each at baseline (c) and at three and six month after the first treatment. Results are shown at one (M1; d), three (M3; e) and seven (M7; f) month after the first treatment.

\section{References}

Ader, M. and E.M. Tanaka. 2014. "Modeling human development in 3D culture." Current Opinion in Cell Biology 31, 23-28.

Al-Drees, M. A. et al. 2015. „Making Blood: The Haematopoietic Niche Throughout Ontogeny.” Stem Cells International 2015, 571893.

Alexander, C. E. and S. C. Dulebohn. 2018. „Lumbosacral Facet Syndrome”, StatPearls [Internet], Treasure Island (FL): StatPearls Publishing; 2018-. 2017 Nov 5. (available online at https://www.ncbi.nlm.nih.gov/books/NBK441906/).

Alt, E. et al. 2011. „Fibroblasts Share Mesenchymal Phenotypes with Stem Cells, but Lack their Differentiation and Colony-Forming Potential”, Biology of the Cell 103, 197-208.

Alt, E. 2015. „Mesenchymal Stem Cell - What Is in the Name?”, Modern Medicine 22, 193-196.

Altman, A. M. et al. 2009. " IFATS Collection: Human AdiposeDerived Stem Cells Seeded on a Silk Fibroin-Chitosan Scaffold Enhance Wound Repair in a Murine Soft Tissue Injury Model", Stem Cells 27:250-258.

Altman, A. M. et al. 2010. "Human Tissue-Resident Stem Cells Combined with Hyaluronic Acid Gel Provide FibrovascularIntegrated Soft-Tissue Augmentation in a Murine Photoaged Skin Model", Plastic and Reconstructive Surgery 125, 1-11.

Altman, A. M. et al. "Adipose Tissue-Derived Stem Cells Enhance Bioprosthetic Mesh Repair of Ventral Hernias", Plastic and Reconstructive Surgery 126, 845-854.

Altman, A. M. et al. 2011. „Wound Microenvironment Sequesters Adipose-Derived Stem Cells in a Murine Model of Reconstructive Surgery in the Setting of Concurrent Distant Malignancy”, Plastic and Reconstructive Surgery 127, 1467-1477.

Andriolo, L. et al. 2018. „Regenerative Therapies Increase 
Survivorship of Avascular Necrosis of the Femoral Head: A Systematic Review and Meta-Analysis”, International Orthopaedics 42: 1689-1704.

Aronowitz, J. A., and J. D. I. Ellenhorn. 2013. „Adipose Stromal Vascular Fraction Isolation: A Head-To-Head Comparison of Four Commercial Cell Separation Systems”, Plastic and Reconstructive Surgery 132, 932e-939e.

Aronowitz, J. A. et al. 2016. „Adipose Stromal Vascular Fraction Isolation: A Head-To-Head Comparison of 4 Cell Separation Systems \#2”, Annals of Plastic Surgery 77, 354-362.

Avolio, E. and P. Madeddu. 2016. „Discovering Cardiac Pericyte Biology: From Physiopathological Mechanisms to Potential Therapeutic Applications in Ischemic Heart Disease”, Vascular Pharmacology 86, 53-63.

Bai, X. et al. 2007. „VEGF Receptor Flk-1 Plays an Important Role in C-Kit Expression in Adipose Tissue Derived Stem Cells”, FEBS Letters 581, 4681-4684.

Bai, X. et al. 2011. „Tracking Long-Term Survival of Intramyocardially Delivered Human Adipose Tissue-Derived Stem Cells Using Bioluminescence Imaging" Molecular Imaging and Biology 13, 633-645.

Belema Bedada, F., A. Technau, H. Ebelt, M. Schulze and T. Braun. 2005. „Activation of Myogenic Differentiation Pathways in Adult Bone Marrow-Derived Stem Cells", Molecular and Cellular Biology 25, 9509-9519.

Binamé, F. 2014. Transduction of Extracellular Cues into Cell Polarity: The Role of the Transmembrane Proteoglycan NG2", Molecular Neurobiology 50, 482-493.

Bourin, P. et al. 2013. „Stromal Cells From the Adipose TissueDerived Stromal Vascular Fraction and Culture Expanded Adipose Tissue-Derived Stromal/Stem Cells: A Joint Statement of the International Federation for Adipose Therapeutics and Science (IFATS) and the International Society for Cellular Therapy (ISCT)”, Cytotherapy 15, 641-648.

Bradshaw, A. D. 2016. „The Role of Secreted Protein Acidic and Rich in Cysteine (SPARC) in Cardiac Repair and Fibrosis: Does Expression of SPARC by Macrophages Influence Outcomes?”, Journal of Molecular and Cellular Cardiology 93, 156-161.

Brekken, R. A. and E.H. Sage. „SPARC, a Matricellular Protein: At the Crossroads of Cell-Matrix Communication”, Matrix Biology 19, 816827.

Breunig, .J J. et al. 2007. „Everything That Glitters Isn't Gold: A Critical Review of Postnatal Neural Precursor Analyses”, Cell Stem Cell 1, 612-627.

Brinkley, B. R. et al. 1980. "Variations in Cell Form and Cytoskeleton in Human Breast Carcinoma Cells In Vitro", Cancer Research 40, 3118-3129

Bruno, I. et al. 2014. „Characterization of Nucleated Cells From Equine Adipose Tissue and Bone Marrow Aspirate Processed for Point-ofCare Use”, Journal of Equine Veterinary Science 34, 1118-1127.

Caplan, A. I. 2017. „Mesenchymal Stem Cells: Time to Change the Name!”, Stem Cells Translational Medicine 6, 1445-1451.

Caruso, S. and I.K.H. Poon. 2018. „Apoptotic Cell-Derived Extracellular Vesicles: More Than Just Debris”, Frontiers in Immunology 9, 1486.

Chiodoni, C., M. P. Colombo and S. Sangaletti. 2010. „Matricellular Proteins: From Homeostasis to Inflammation, Cancer, and Metastasis”, Cancer and Metastatis Reviews 29, 295-307.

Choi, Y. A. et al. 2010. „Secretome Analysis of Human BMSCs and Identification of SMOC1 as an Important ECM protein in Osteoblast Differentiation”, Journal of Proteome Research 9, 2946-2956.

Clark, R. A. 1990. „Fibronectin matrix deposition and fibronectin receptor expression in healing and normal skin”, Journal of Investigative Dermatology 94, 128S-134S.
Condé-Green, A., et al. 2016. „Shift Toward Mechanical Isolation of Adipose-Derived Stromal Vascular Fraction: Review of Upcoming Techniques”, Plastic and Reconstructive Surgery - Global Open 4, e1017.

Corselli, M. et al. 2012. „The Tunica Adventitia of Human Arteries and Veins As a Source of Mesenchymal Stem Cells”, Stem Cells and Development 21, 1299-1308.

Coudreuse, D. and H. C. Korswagen. 2007. „The Making of Wnt: New Insights into Wnt Maturation, Sorting and Secretion”, Development 134, 3-12

Crisan, M. et al. 2012. „Perivascular Cells for Regenerative Medicine”, Journal of Molecular and Cellular Medicine 16, 2851-2860

Damia, E. et al. 2018. „Adipose-Derived Mesenchymal Stem Cells: Are They a Good Therapeutic Strategy for Osteoarthritis?” International Journal of Molecular Sciences 19: pii: E1926.

da Silva Meirelles, L., P. C. Chagastelles and N. B. Nardi. 2006. „Mesenchymal Stem Cells Reside in Virtually all Post-Natal Organs and Tissues”, Journal of Cell Science 119, pp. 2204-2213.

de Almeida, P. E., J. R. van Rappard and J. C. Wu. 2011. „In Vivo Bioluminescence for Tracking Cell Fate and Function”, American Journal of Physiology--Heart and Circulatory Physiology 301, H663-H671

Demidova-Rice, T.N., M.R. Hamblin and I.M. Herman. 2012. „Acute and Impaired Wound Healing: Pathophysiology and Current Methods for Drug Delivery, Part 1: Normal and Chronic Wounds: Biology, Causes, and Approaches To Care”, Advances in Skin \& Wound Care 25, 304-314.

de Souza, L. E. B. et al. 2016. „Mesenchymal Stem Cells and Pericytes: To What Extent Are They Related?”, Stem Cells and Development 25, 1843-1852.

Diaz-Flores, L. et al. 1991. „Microvascular Pericytes: A Review of their Morphological and Functional Characteristics”, Histology and Histopathology 6, 269-286.

Di Russo, J. et al. 2017. „Vascular Laminins in Physiology and Pathology”, Matrix Biology 57-58, 140-148.

Dominici, M. et al. 2006. „Minimal Criteria for Defining Multipotent Mesenchymal Stromal Cells. The International Society for Cellular Therapy Position Statement”, Cytotherapy 8, 315-317.

Dong, L., H. Hao, W. Han \& X Fu. 2015. „The Role of the Microenvironment on the Fate of Adult Stem Cells”, Science China. Life Sciences 58, 639-648.

D’Ippolito, G. et al. 2006. „Sustained Stromal Stem Cell Self-Renewal and Osteoblastic Differentiation During Aging”, Rejuvenation Research 9, 10-19.

Dvorak, H. F. 2015. „Tumors: Wounds That Do Not Heal-Redux”, Cancer Immunology Research 3, 1-11.

Farah, Z. et al. 2016. „A Concise Review of Common Animal Models for the Study of Limb Regeneration”, Organogenesis 12, 109-118.

Fernández-Klett, F. and J. Priller. 2015. „Diverse Functions of Pericytes in Cerebral Blood Flow Regulation and Ischemia”, Journal of Cerebral Blood Flow \& Metabolism 35, 883-887.

Flier, J. S., L. H. Underhill and H.F. Dvorak. 1986. „Tumors: Wounds That Do Not Heal”, New England Journal of Medicine 315, 16501659.

Freitag, J. et al. 2017. „Effect of autologous adipose-derived mesenchymal stem cell therapy in the treatment of a post-traumatic chondral defect of the knee”, BMJ Case Reports pii: bcr-2017220852.

Friedenstein, A. J. et al. 1968. „Heterotopic of Bone Marrow. Analysis of Precursor Cells for Osteogenic and Hematopoietic Tissues”, Transplantation 6, 230-247.

Friedenstein, A. J. et al. 1974. „Precursors for Fibroblasts in Different Populations of Hematopoietic Cells as Detected by the In Vitro Colony Assay Method”, Experimental Hematology 2, 83-92. 
Fuchs, B. J. Schiller and M. A. Cross. 2007. „Apoptosis-Associated Changes in the Glycerophospholipid Composition of Hematopoietic Progenitor Cells Monitored by 31P NMR Spectroscopy and MALDITOF Mass Spectrometry", Chemistry and Physics of Lipids 150, 229-238.

Fujikawa, T. et al. 2005. „Teratoma Formation Leads to Failure of Treatment for Type I Diabetes Using Embryonic Stem Cell-Derived Insulin-Producing Cells”, The American Journal of Pathology 166, 1781-1791.

Galleu, A. et al. 2017. „Apoptosis in Mesenchymal Stromal Cells Induces In Vivo Recipient-Mediated Immunomodulation”, Science Translational Medicine 9, eaam7828.

Gehmert, S. et al. 2010. „Breast Cancer Cells Attract the Migration of Adipose Tissue-Derived Stem Cells via the PDGF- BB/PDGFR- $\beta$ Signaling Pathway", Biochemical and Biophysical Research Communications 398, 601-605.

Gimble, J. M., F. Guilak and B. A. Bunnell. 2010. „Clinical and Preclinical Translation of Cell-Based Therapies using Adipose Tissue-Derived Cells” Stem Cell Research \& Therapy 1, 19.

Gir, P. et al. 2012. „Human Adipose Stem Cells: Current Clinical Applications”, Plastic and Reconstructive Surgery 129, 1277-1290.

González, M.A. et al. 2009. „Adipose-Derived Mesenchymal Stem Cells Alleviate Experimental Colitis by Inhibiting Inflammatory and Autoimmune Responses", Gastroenterology 136, 978-89.

Grillo, M., N. Konstantinides and M. Averof. 2016. „Old Questions, New Models: Unraveling Complex Organ Regeneration With New Experimental Approaches”, Current Opinion in Genetics \& Development 40, 23-31.

Guillemin, G. J. and B. J. Brew. 2004. „Microglia, Macrophages, Perivascular Macrophages, and Pericytes: A Review of Function and Identification”, Journal of Leukocyte Biology 75, 388-397.

Haas, B. J. and J. L. Whited. 2017. „Advances in Decoding Axolotl Limb Regeneration”, Trends in Genetics 33, 553-565.

Haenel, A. et al. 2018. „Unmodified, Autologous Adipose-Derived Regenerative Cells Improve Cardiac Function, Structure and Revascularization in a Porcine Model cf Chronic Myocardial Infarction”, DOI: https://doi.org/10.1101/286468.

Heffernan, C., H. Sumer and P.J. Verma. 2011. „Generation of Clinically Relevant „Induced Pluripotent Stem“ (iPS) Cells." Journal of Stem Cells 6, 109-127.

Hochreiter-Hufford, A. and K. S. Ravichandran. 2013. „Clearing the Dead: Apoptotic Cell Sensing, Recognition, Engulfment, and Digestion”, Cold Spring Harbor Perspectives in Biology 5, a008748.

Hoffman, A. M. and S. W. Dow. 2016. „Concise Review: Stem Cell Trials Using Companion Animal Disease Models”, Stem Cells 34, 1709-1729.

Holland, P. W. et al. 1987. „In Vivo Expression of mRNA for the Ca++-Binding Protein SPARC (Osteonectin) Revealed by In Situ Hybridization”, Journal of Cellular Biology 105, 473-482.

Holmes, C. and W.L. Stanford. 2007. „Concise Review: Stem Cell Antigen-1: Expression, Function, and Enigma”, Stem Cells 25, 13391347.

Ilmer, M. et al. 2014. „Two Sides of the Same Coin: Stem Cells in Cancer and Regenerative Medicine”, The FASEB Journal 28, 27482761.

Ismail, N. et al. 2013. „Macrophage Microvesicles Induce Macrophage Differentiation and miR-223 Transfer”, Blood 121, 984-995.

Izadpanah, R. et al. 2006. „Biologic Properties of Mesenchymal Stem Cells Derived from Bone Marrow and Adipose Tissue”, Journal of Cellular Biochemistry 99, 1285-1297.

Jellinger, K. A. and J. Attems. 2013. „Neuropathological Approaches to Cerebral Aging and Neuroplasticity”, Dialogues in Clinical Neuroscience 15, 29-43.

Jo, C. H. et al. 2014. " Intra-Articular Injection of Mesenchymal Stem
Cells for the Treatment of Osteoarthritis of the Knee: A Proof-ofConcept Clinical Trial", Stem Cells 32,1254-1266.

Jullien, J. et al. 2011. „Mechanisms of Nuclear Reprogramming by Eggs and Oocytes: A Deterministic Process?" Nature Reviews. Molecular Cell Biology, 12, 453-459.

Jung, C. K. 2014. „Articular Cartilage: Histology and Physiology”, In: Shetty, A. A. et al. (eds), "Techniques in Cartilage Repair Surgery", Springer, Berlin, pp. 17-21.

Kara, R. J. et al. 2011. „Fetal Cells Traffic to Injured Maternal Myocardium and Undergo Cardiac Differentiation”, Circulation Research 110:82-93.

King, N. M. and J. Perrin. 2014. „Ethical Issues in Stem Cell Research and Therapy", Stem Cell Research \& Therapy 5, 85.

Klein, S. M. et al. 2016. "Peripheral Motor and Sensory Nerve Conduction following Transplantation of Undifferentiated Autologous Adipose Tissue-Derived Stem Cells in a Biodegradable U.S. Food and Drug Administration-Approved Nerve Conduit", Plastic and Reconstructice Surgery 138, 132-139.

Konstantinow, A. et al. 2017. „Therapy of Ulcus Cruris of Venous and Mixed Venous Arterial Origin with Autologous, Adult, Native Progenitor Cells from Subcutaneous Adipose Tissue: A Prospective Clinical Pilot Study", Journal of the European Academy of Dermatology and Venereology 38, 42-49.

Koyanagi, M. et al. 2005. „Cell-to-Cell Connection of Endothelial Progenitor Cells with Cardiac Myocytes by Nanotubes: A Novel Mechanism for Cell Fate Changes?”, Circulation Research 96, 1039_ 1041.

Krampera, M. et al. 2003. „Bone Marrow Mesenchymal Stem Cells Inhibit the Response of Naive and Memory Antigen-Specific T Cells to Their Cognate Peptide”, Blood 101, 3722-3729.

Kruger, S. et al. 2014. „Molecular Characterization of Exosome-Like Vesicles from Breast Cancer Cells”, BMC Cancer 14, 44.

Kusuma, G. D. et al. (2017) „Effect of the Microenvironment on Mesenchymal Stem Cell Paracrine Signaling: Opportunities to Engineer the Therapeutic Effect”, Stem Cells and Development 26, 617-631.

Lalu, M. M. et al. 2012. "Safety of Cell Therapy with Mesenchymal Stromal Cells (SafeCell): A Systematic Review and Meta-Analysis of Clinical Trials", PLoS One 7, e47559.

Lane, T. F. and E. H. Sage. 1994. „The Biology of SPARC, a Protein that Modulates Cell-Matrix Interactions”, The FASEB Journal 8 , 163-173.

Larson, E. et al. 2018. "Early-Stage Osteonecrosis of the Femoral Head: Where Are We and Where Are We Going in Year 2018?”, International Orthopaedics 42, 1723-1728.

Lauber, K. et al. 2003. „Apoptotic Cells Induce Migration of Phagocytes via Caspase-3-Mediated Release of a Lipid Attraction Signal”, Cell 113, 717-730.

Lee, A. S. et al. 2013. „Tumorigenicity as a Clinical Hurdle for Pluripotent Stem Cell Therapies” Nature Medicine 19, 998-1004.

Lee, A. S. et al. 2017. „Brief Report: External Beam Radiation Therapy for the Treatment of Human Pluripotent Stem Cell-Derived Teratomas”, Stem Cells 35, 1994-2000.

Leto Barone, A. A. et al. 2013. „Immunomodulatory effects of adiposederived stem cells: fact or fiction?", BioMed Research International 2013, 383685.

Malliaras, K. et al. 2013. „Cardiomyocyte Proliferation and Progenitor Cell Recruitment Underlie Therapeutic Regeneration after Myocardial Infarction in the Adult Mouse Heart”, EMBO Molecular Medicine 5, 191-209.

Marsoner, F., P. Koch and J. Ladewig 2018. „Cortical Organoids: Why All This Hype?” Current Opinion in Genetics \& Development 52, 22-28.

McCusker, C. and D. M. Gardiner. 2011. "The Axolotl Model for 
Regeneration and Aging Research: A Mini-Review”, Gerontology 57, 565-571.

Metcalf, G. L. 2016. Evaluation of Adipose-Derived Stromal Vascular Fraction from the Lateral Tailhead, Inguinal Region, and Mesentery of Horses." The Canadian Journal of Veterinary Research 80, 294301.

Metzele, R. et al. 2011. „Human Adipose Tissue-Derived Stem Cells Exhibit Proliferation Potential and Spontaneous Rhythmic Contraction after Fusion with Neonatal Rat Cardiomyocytes”, The FASEB Journal 25, 830-839.

Muehlberg, F. L. et al. 2009. "Tissue-Resident Stem Cells Promote Breast Cancer Growth and Metastasis." Carcinogenesis 30, 589-597.

Murphy, M. B., K. Moncivais and A. I. Caplan. 2013. „Mesenchymal Stem Cells: Environmentally Responsive Therapeutics for Regenerative Medicine”, Experimental and Molecular Medicine 45, e54.

Murphy-Ullrich, J.E. and E.H. Sage. 2014. „Revisiting the matricellular concept“, Matrix Biology: Journal of the International Society for Matrix Biology 37, 1-14.

Neth, P. et al. 2007. „The Wnt Signal Transduction Pathway in Stem Cells and Cancer Cells: Influence on Cellular Invasion”, Stem Cell Reviews 3, 18-29.

Nie, J. et al. 2008. „IFATS Collection: Combinatorial Peptides Identify Alpha5beta1 Integrin as a Receptor for the Matricellular Protein SPARC on Adipose Stromal Cells”, Stem Cells 26, 2735-2745.

Oberbauer, E. et al. 2015. „Enzymatic and Non-Enzymatic Isolation Systems for Adipose Tissue-Derived Cells: Current State of the Art." Cell Regeneration 4, 7.

Oh, K. et al. 2015. "In Vivo Differentiation of Therapeutic InsulinProducing Cells from Bone Marrow Cells via Extracellular VesicleMimetic Nanovesicles”, ASC Nano 9, 11718-11727.

Pak, J. et al. 2014. „Complete Resolution of Avascular Necrosis of the Human Femoral Head Treated with Adipose Tissue-Derived Stem Cells and Platelet-Rich Plasma”, Journal of International Medical Research 42, 1353-1362.

Pan, Q. et al. 2014. "Detection of Spontaneous Tumorigenic Transformation During Culture Expansion of Human Mesenchymal Stromal Cells“, Experimental Biology and Medicine 239, 105-115.

Pers, Y. M. 2016. "Adipose Mesenchymal Stromal Cell-Based Therapy for Severe Osteoarthritis of the Knee: A Phase I Dose-Escalation Trial", Stem Cells Translational Medicine 5, 847-856.

Phinney, D. G. and D. J. Prockop. 2007. „Concise Review: Mesenchymal Stem/Multipotent Stromal Cells: The State of Transdifferentiation and Modes of Tissue Repair-Current Views", Stem Cells 25, 2896-2902.

Pittenger, M. F. et al. 1999. „Multilineage Potential of Adult Human Mesenchymal Stem Cells”, Science 284, 143-147.

Pourjafar, M. et al. 2017. „All-Trans Retinoic Acid Enhances In Vitro Mesenchymal Stem Cells Migration by Targeting Matrix Metalloproteinases 2 and 9", Biotechnology Letters 39, 1263-1268.

Ra, J. C. et al. 2011. „Safety of Intravenous Infusion of Human Adipose Tissue-Derived Mesenchymal Stem Cells in Animals and Humans”, Stem Cells and Development. 20, 1297-1308.

Rakic, P. 1985. „DNA Synthesis and Cell Division in the Adult Primate Brain”, Annals of the New York Academy of Sciences 457, 193-211.

Ratajczak, M. Z. 2015. „A Novel View of the Adult Bone Marrow Stem Cell Hierarchy and Stem Cell Trafficking”, Leukemia 29, 776782.

Rezza, A., Sennett, R. and Rendl, M. 2014. Adult Stem Cell Niches: Cellular and Molecular Components. Current Topics in Developmental Biology 107, 333-372.

Ricci-Vitiani, L. et al. 2010. „Tumour Vascularization via Endothelial Differentiation of Glioblastoma Stem-Like Cells”, Nature 468, 824828.
Riggs, J. W. et al. 2013 „Induced Pluripotency and Oncogenic Transformation are Related Processes”, Stem Cells Dev 22, 37-50.

Rieppo, J. et al. 2008. „Practical Considerations in the Use of Polarized Light Microscopy in the Analysis of the Collagen Network in Articular Cartilage”, Microscopy Research and Technique 71, 279287.

Røsland, G. V. et al. 2009. Long-Term Cultures of Bone MarrowDerived Human Mesenchymal Stem Cells Frequently Undergo Spontaneous Malignant Transformation. Cancer Research 69, 53315339.

Rothoerl, R. et al. 2016. "Clinical Results of Adipose Derived Stem Cell Injection for Facet Joint Syndrome”, IFATS San Diego 2016 Conference Proceedings, p. 79 (available online at https://www.ifats.org/assets/docs/IFATS-Program-Book-2016FINAL-11.23.16.pdf; accessed on August 08, 2018).

Sá da Bandeira, D., J. Casamitjana and M. Crisan M. 2017. „Pericytes, Integral Components of Adult Hematopoietic Stem Cell Niches”, Pharmacology \& Therapeutics 171, 104-113.

Sadat, S. et al. 2007. „The Cardioprotective Effect of Mesenchymal Stem Cells is Mediated by IGF-I and VEGF", Biochemical and Biophysical Research Communications 363, 674-679.

Satoh, A., K. Mitogawa and A. Makanae. 2015. „Regeneration Inducers in Limb Regeneration”, Development Growth \& Differentiation 57, 421-429.

Scarfe, L. et al. 2017. „Preclinical Imaging Methods For Assessing the Safety and Efficacy of Regenerative Medicine Therapies”, npj Regenerative Medicine 2, 28.

Schäffler, A. and C. Büchler. 2007. „Concise Review: Adipose TissueDerived Stromal Cells-Basic and Clinical Implications for Novel Cell-Based Therapies”, Stem Cells 25, 818-827.

Serini, G., D. Valdembri and F. Bussolino. 2006. „Integrins and Angiogenesis: a Sticky Business”, Experimental Cell Research 312, 651-658.

Shaik, S. et al. (2018). „Effects of Decade Long Freezing Storage on Adipose Derived Stem Cells Functionality”, Scientific Reports 8, 8162.

Shi, Y., H. Inoue, J.C. Wu and S. Yamanaka. 2017. „Induced pluripotent stem cell technology: a decade of progress." Nature Reviews. Drug Discovery 16, 115-130.

Sims, D. E. 1986. „The Pericyte - A Review”, Tissue and Cell 18, 153174.

Solakoglu, Ö. et al. 2019. „Improved guided bone regeneration by combined application of unmodified, fresh autologous adipose derived regenerative cells and plasma rich in growth factors - a firstin-human pilot study”, World Journal of Stem Cells 11, 124-146.

Song, Y.-H., L. Prantl, and E. Alt. 2011. „Differentiation and Plasticity of Stem Cells for Tissue Engineering”, in Tissue Engineering, Pallua N, Suscheck CV (Eds.) Springer Publishing, pp. 113-130.

Sorice, S. et al. 2016. „, The Role of Stem Cell Therapeutics in Wound Healing: Current Understanding and Future Directions”, Plastic and Reconstructive Surgery 138, 31S-41S.

Steinemann, D., G. Göhring and B. Schlegelberger. 2013. „Genetic Instability of Modified Stem Cells - A First Step Towards Malignant Transformation?”, American Journal of Stem Cells 2, 39-51.

Suzuki, S. et al. (2010). „The Neural Stem/Progenitor Cell Marker Nestin is Expressed in Proliferative Endothelial Cells, but Not in Mature Vasculature”, Journal of Histochemistry and Cytochemistry 58, 721-730.

Swijnenburg, R. J. et al. 2005. „Embryonic Stem Cell Immunogenicity Increases upon Differentiation after Transplantation into Ischemic Myocardium”, Circulation 112, I166-I172.

Tai, M. H. et al. 2004. „Oct4 Expression in Adult Human Stem Cells: Evidence in Support of the Stem Cell Theory of Carcinogenesis”, Carcinogenesis 26, 495-502. 
Takahashi, K. et al. 2007. „Induction of Pluripotent Stem Cells from Adult Human Fibroblasts by Defined Factors”, Cell 131, 861-872.

Te Boekhorst, V., L. Preziosi and P. Friedl. 2016. „Plasticity of Cell Migration In Vivo and In Silico", Annual Review of Cell and Developmental Biology 32, 491-526.

Toyserkani, N. M. et al. 2017. „Concise Review: A Safety Assessment of Adipose-Derived Cell Therapy in Clinical Trials: A Systematic Review of Reported Adverse Events”, Stem Cells Translational Medicine 6, 1786-1794.

Trosko, J. E. 2014. „Induction of iPS Cells and of Cancer Stem Cells: The Stem Cell or Reprogramming Hypothesis of Cancer?”, The Anatomical Record 297, 161-173.

Tseng, C. and M. G. Kolonin. 2016. „Proteolytic Isoforms of SPARC Induce Adipose Stromal Cell Mobilization in Obesity“, Stem Cells 34, 174-190.

Tung, P.-Y. and P. S. Knoepfler (2015) „Epigenetic Mechanisms of Tumorigenicity Manifesting in Stem Cells”, Oncogene 34, 22882296.

Valadi, H. et al. 2007. „Exosome-Mediated Transfer of mRNAs and microRNAs is a Novel Mechanism of Genetic Exchange between Cells”, Nature Cell Biology 9, 654-659.

Van Dongen J.A. et al. 2018. „Comparison of Intraoperative Procedures for Isolation of Clinical Grade Stromal Vascular Fraction for Regenerative Purposes: A Systematic Review” Journal of Tissue Engineering and Regenerative Medicine 12, e261-e274.

Vazin, T. and W. J. Freed. 2010. „Human Embryonic Stem Cells: Derivation, Culture, and Differentiation: A Review”, Restorative Neurology and Neuroscience 28, 589-603.

Vega, M. E. and J.E. Schwarzbauer. 2016. „Collaboration of Fibronectin Matrix with Other Extracellular Signals in Morphogenesis and Differentiation”, Current Opinion in Cell Biology 42, 1-6.

Velten, L. et al. 2017. „Human Haematopoietic Stem Cell Lineage Commitment is a Continuous Process”, Nature Cell Biology 19, 271 281.
Wabik, A. and P.H. Jones 2015. „Switching Roles: The Functional Plasticity of Adult Tissue Stem Cells“, The EMBO Journal 34, 1164 1179.

Wang, R. et al. 2010. „Glioblastoma Stem-Like Cells Give Rise to Tumor Endothelium”, Nature 468, 829-833.

Willert, K. et al. 2003. „Wnt Proteins are Lipid-Modified and Can Act as Stem Cell Growth Factors”, Nature 423, 448-452.

Xin, H. et al. 2012. „Exosome-Mediated Transfer of miR-133b from Multipotent Mesenchymal Stromal Cells to Neural Cells Contributes to Neurite Outgrowth”, Stem Cells 30, 1556-1564.

Xu, J. Y., G. H. Chen and Y. J. Yang. 2017. „Exosomes: A Rising Star in Falling Hearts”, Frontiers in Physiology 8, 494.

$\mathrm{Xu}$, S. et al. 2012. „In Vitro Expanded Bone Marrow-Derived Murine (C57bl/kalwrij) Mesenchymal Stem Cells Can Acquire CD34 Expression and Induce Sarcoma Formation In Vivo“, Biochemical and Biophysical Research Communications 424, 391-397

Yamamoto, R. et al. 2013. „Clonal Analysis Unveils Self-Renewing Lineage-Restricted Progenitors Generated Directly from Hematopoietic Stem Cells”, Cell 154, 1112-1126.

Yoshimura, K. et al. 2006. „Characterization of Freshly Isolated and Cultured Cells Derived from the Fatty and Fluid Portions of Liposuction Aspirates”, Journal of Cellular Physiology 208, 64-76.

Yu, J. et al. 2007. „Induced Pluripotent Stem Cell Lines Derived from Human Somatic Cells”, Science 318, 1917-1920.

Yukawa, H. et al. 2009. „Quantum Dots for Labeling Adipose TissueDerived Stem Cells”, Cell Transplantation 18, 591-599.

Zhang, B. et al. 2015. „HucMSC-Exosome Mediated-Wnt4 Signaling is Required for Cutaneous Wound Healing”, Stem Cells 33, 2158-2168.

Zielins, E. R. et al. 2016. „The Role of Stem Cells in Limb Regeneration”, Organogenesis 12, 16-27.

Zuk, P. A. et al. 2001. „Multilineage Cells from Human Adipose Tissue: Implications for Cell-Based Therapies”, Tissue Engineering 7, 211-228.

\section{Short CV of Dr. Eckhard U. Alt}

Eckhard U. Alt, MD, PhD, is Professor of Medicine at the Technical University of Munich (Munich, Germany), Professor at Tulane University (New Orleans, LA, USA), is the Todd and Linda Broin Distinguished Professor and Chair at The Sanford Project (Sioux Falls, SD, USA) and was Professor at the University of Texas MD Anderson Cancer Center (Houston, TX, USA). Dr. Alt received his medical degree as Valedictorian from Heidelberg University (Heidelberg, Germany). After two years in cardiac surgery at the Ludwig Maximilians University of Munich (Munich, Germany), he completed his education at the Department of Internal Medicine/Cardiology at the Klinikum rechts der Isar of the Technical University of Munich and became one of the youngest professors there. He is a frequent reviewer and serves on the Editorial Boards of respected journals. From 2001 to 2007, he was President of the International Cardiac Pacing and Electrophysiology Society. Prof. Alt has organized major national and international congresses, authored more than 500 publications in peer reviewed journals, books and book chapters. His scientific publications have been cited by other scientists more than 28.000 times, and his scientific h factor is $\mathbf{8 0}$. He is a highly sought after global lecturer. His innovative spirit is demonstrated by more than 750 world-wide patents he has been granted, primarily in the fields of Electrophysiology, Interventional Cardiology and Stem Cells. He has introduced an impressive number of new therapies to clinical practice, including novel methods and devices such as Rate-adaptive Pacing, Defibrillators, Treatment of Atrial Fibrillation and Stem Cell Treatment. His contributions have substantially influenced the modern practice of medicine. Prof. Alt was elected among the leading 1,000 physicians in Germany, the magazine 'Focus' rated him among the "Best 12 Cardiologists in Germany". He received the Hahn Research Award from the European Society of Thoracic Surgery and the prestigious Andreas Gruentzig Ethica Award as Best Experimental Researcher from the Erasmus University in Rotterdam. He is honorary member of several European Medical Societies. In 2009 he was named Entrepreneur of the Year in Munich; Health Care Hero and Innovator of the Year in Houston, TX. He is Chairman of the Board of the Isar Klinikum in Munich and of InGeneron Inc. in Houston TX. In addition to being a reknown physician, scientist, profilic researcher and inventor, Prof. Alt is deeply committed to charity in Germany, USA and Africa. 